\title{
CAMA
}

Centre for Applied Macroeconomic Analysis

\section{Foreign Reserve Accumulation and the Mercantilist Motive Hypothesis}

\section{CAMA Working Paper 18/2014 February 2014}

\section{Patrick Carvalho}

Crawford School of Public Policy

Research School of Economics and

Centre for Applied Macroeconomic Analysis, ANU

\section{Renee A. Fry-McKibbin}

Crawford School of Public Policy and

Centre for Applied Macroeconomic Analysis, ANU

\begin{abstract}
A fivefold increase in central bank foreign reserves across the globe over the past fifteen years has prompted the question of whether this constitutes a new form of mercantilism. According to this view, countries accumulate foreign reserves in order to support export promotion by influencing exchange rates and/or to signal relative economic strength as a modern version of bullionism. Using a unique dataset on daily foreign exchange intervention, this paper investigates the mercantilist motive hypothesis for the case of Brazil over the period 2009-2012. The findings support reserve accumulation as a byproduct of successful central bank intervention in the Brazilian foreign exchange market. The results also indicate regional currency intervention spillovers to Brazil's neighbouring countries, including on their foreign reserve build-ups.
\end{abstract}




\section{Keywords}

Foreign exchange intervention, currency intervention, exchange rate volatility, reserve accumulation, factor model, emerging markets

\section{JEL Classification}

F31, F36, F41

\section{Address for correspondence:}

(E) cama.admin@anu.edu.au

The Centre for Applied Macroeconomic Analysis in the Crawford School of Public Policy has been established to build strong links between professional macroeconomists. It provides a forum for quality macroeconomic research and discussion of policy issues between academia, government and the private sector.

The Crawford School of Public Policy is the Australian National University's public policy school, serving and influencing Australia, Asia and the Pacific through advanced policy research, graduate and executive education, and policy impact. 


\title{
Foreign Reserve Accumulation and the Mercantilist Motive Hypothesis*
}

\author{
Patrick Carvalho ${ }^{\dagger \ddagger}$ and Renée A. Fry-McKibbin ${ }^{\dagger}$ \\ ${ }^{\dagger}$ Centre for Applied Macroeconomic Analysis \\ Crawford School of Public Policy \\ The Australian National University \\ ${ }^{\ddagger}$ Research School of Economics \\ The Australian National University
}

February 2014

\begin{abstract}
A fivefold increase in central bank foreign reserves across the globe over the past fifteen years has prompted the question of whether this constitutes a new form of mercantilism. According to this view, countries accumulate foreign reserves in order to support export promotion by influencing exchange rates and/or to signal relative economic strength as a modern version of bullionism. Using a unique dataset on daily foreign exchange intervention, this paper investigates the mercantilist motive hypothesis for the case of Brazil over the period 20092012. The findings support reserve accumulation as a by-product of successful central bank intervention in the Brazilian foreign exchange market. The results also indicate regional currency intervention spillovers to Brazil's neighbouring countries, including on their foreign reserve build-ups.
\end{abstract}

Keywords: Foreign exchange intervention, currency intervention, exchange rate volatility, reserve accumulation, factor model, emerging markets

JEL Classification: F31, F36, F41

${ }^{*}$ Corresponding author is Renée McKibbin: renee.mckibbin@anu.edu.au. The authors express gratitute to the Central Bank of Brazil for the data on the currency intervention in the Brazilian foreign exchange market. 


\section{Introduction}

The fivefold increase in global central bank foreign reserves over the past fifteen years is sometimes interpreted as a by-product of a new mercantilist approach of emerging countries. In a series of papers Dooley et al. (2005, 2007, 2008, 2009) describe a current 'Revived Bretton Woods' system (BWII) which consists of emerging countries using currency intervention, and consequent reserve accumulation as a methodical way of affecting national currency levels to support export promotion. Aizenman and Lee (2008) dispute the BWII framework by de-emphasizing the relationship between reserve hoarding and the goal to depreciate (or retard appreciation of) national currencies. Indeed, in accordance with their critique, the main driver of recent reserve build-ups is to prevent or mitigate currency crises - branded the precautionary or self insurance motive hypothesis. This is a motive prevalent following the crises in Asia in 19971998 and Latin America in 1998 (Brazil) and 2002 (Argentina), and is characterized by sudden stops (Durdu et al., 2007; Obstfeld et al., 2010; Jeanne and Ranciere, 2011; Calvo et al., 2012).

It is important to understand that the precautionary and mercantilist motives are not necessarily competing concepts, but they might be complementary to each other. While the stock of reserves relates to the pure precautionary motive, the flow into (or out of) reserves may relate to the pure mercantilist motive. Although there are many precautionary reasons to explain the increase in global reserve stocks, especially in emerging economies, the timing of the accumulation might be linked to exportoriented countries facing currency appreciation forces. In this case, both hypotheses might fall under a broader mercantilist approach.

This paper empirically investigates elements of the mercantilist motive hypothesis using a unique daily data set on Brazil's foreign exchange intervention from 2009 to 2012. ${ }^{1}$ Although we do not know for sure whether the central bank intervenes for pure precautionary or pure mercantilist motives, or a mix of both, our intuition is that the mercantilist motive dominates, at least over the sample period for which we have data. Several case studies on the effects of Brazilian currency intervention and reserve accumulation in the Latin American region are conducted in this paper. These case studies are important in that they are able to inform policy debate on several junctures,

\footnotetext{
${ }^{1}$ The intervention data is kindly provided to the authors by the Central Bank of Brazil. This type of data is unavailable prior to mid 2009, making the analysis applicable to the behaviour of Brazilan central bank intervention and reserve accumulation in the post 2008 financial crisis period only.
} 
Figure 1a:

Brazil's Foreign Reserve Stocks (US\$bn) vs. Exchange Rate Levels (BRL/USD).

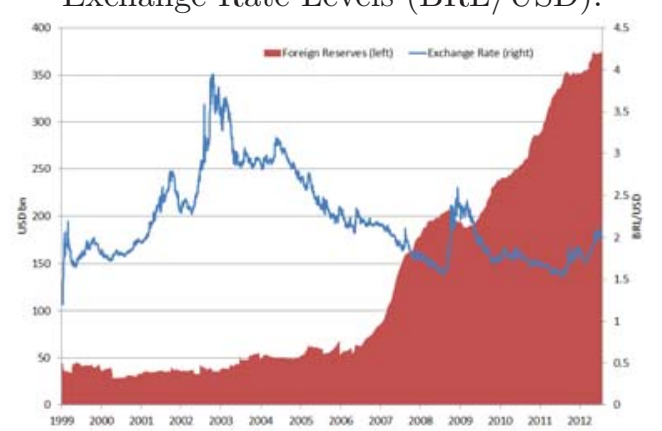

Figure 1b:

Brazil's Consumer Price Index (IPCA, yoy) in percent vs. the Inflation Target Band.

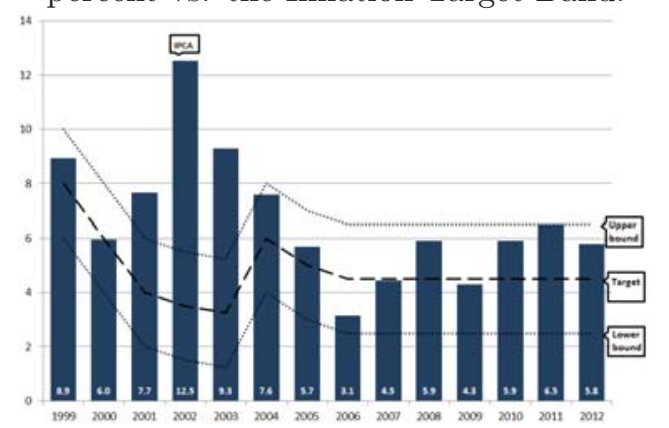

Source: Central Bank of Brazil.

particularly in relation to cross country impacts of domestic policy and the potential for cooperation. First, conclusions relating the effectiveness of intervention and the mercantilist motive in Brazil can be drawn in terms of measuring the effectiveness of intervention for Brazilian currency return volatility. Second, the spillover effects of the mercantilist policy in a major regional country to the exchange rate volatility in its smaller neighboring countries can be analysed. Openness and regional integration would perhaps anticipate such linkages. Third, and related to the previous point, the relationship between regional reserve changes in terms of the spillovers across reserve markets when a major country intervenes can also be analysed. The models estimated provide some evidence on the nature of current regional relationships, establishing the initial conditions if regional cooperation were to be strengthened.

Figure 1a shows Brazil's reserves stock and the Brazilian real exchange rate (BRL) plotted together and Figure $1 \mathrm{~b}$ shows the inflation rates plotted against the target band from 1999 to 2012. In Figure 1a, there is a sharp contrast in reserves levels pre-2007 and post-2007 and this trend appears to begin well before the financial crisis of 2008. In 2007 Brazil became a net external creditor and indeed, a net lender to the International Monetary Fund, once it had accumulated around US $\$ 150 \mathrm{bn}$ in reserves suggesting an element of the precautionary motive. Since then it has more than doubled its reserves to over US\$350bn. ${ }^{2}$ There is no clear view in the literature on whether or

\footnotetext{
${ }^{2}$ The average reserves to GDP ratio for Brazil is 14\% in the 2007-2012 period and is $7 \%$ in the 2000 to 2006 period. Source: World Bank (http://data.worldbank.org/indicator/NY.GDP.MKTP.CD and http://data.worldbank.org/indicator/FI.RES.TOTL.CD). Authors' Calculation.
} 
not this type of strategy is optimal nor is there a clear view on the optimal level of reserves (Obstfeld et al., 2010; Jeanne and Ranciere, 2011). However, there is no reason to expect a structural change in the optimal levels of reserves for Brazil pre-2007 compared to post-2007. As depicted in Figure 1, the real change in this case was in the welcoming environment for mercantilist currency intervention to arise, namely, a strong domestic currency appreciation and controlled inflation expectations. That is, it is more likely that the reason for change was an environment conducive for mercantilist currency intervention to arise, and this is how we frame the arguments in this paper. ${ }^{3}$

One aspect of mercantilist-friendly policy settings that has not received much empirical analysis is the cross-country dynamics of reserve accumulation. There are several possible theoretical explanations for this potential phenomena. First, reserve changes through central bank intervention in one country might trigger reserve changes through central bank intervention in another country in order to maintain relative exchange rates (also known as the 'beggar-thy-neighbour' exchange rate policy). Second, part of the reserve hoarding phenomena might be due to signalling in credit markets. In an environment of asymmetric information, a large accumulation of reserves can signal a country's economic health to market participants, attracting foreign investments and minimizing potential sudden stops or self-fulfilling speculative attacks on its currency. Yet, such reserve accumulation must take into account the reserve stocks of neighboring countries, as economic power is always relative. In this case, game theory might help explain multiple Nash equilibria of reserve stocks between two or more countries. Such a new form of bullionism might be considered as another manifestation of the mercantilist motive for accumulating reserves. In the BWII framework, for instance, Dooley et al. (2005) argue that reserve stocks can be used as collateral for foreign direct

\footnotetext{
${ }^{3}$ Between January 2000 and December 2006, reserves stocks changed little and hovered below US $\$ 50$ bn. Between January 2000 and January 2003, the Brazilian real suffered a massive depreciation leading to little intervention which would further depreciate the currency, as at that time, the exchange rate depreciation was strong enough to stimulate domestic exports. Second, higher levels of the Brazilian real exchange rate jeopardised inflation control (Figure 1b). Between January 2003 and December 2006, the fundamentals of the Brazilian economy improved substantially reflected in a rebounding exchange rate. However, during this time no large changes in reserve stocks are evident, as although appreciating, the exchange rate levels remained above 2.5 BRL/USD, which threatened the achievement of the inflation target (Figure 1b). From mid-2006, inflation was again under control and the exchange rate continued appreciating. Although there is no written rule on acceptable exchange rate levels, from late 2007 the outcry in the media by the domestic manufacturing sector against the fear of a Dutch Disease prompted the mercantilist currency intervention to boost reserve accumulation from around US $\$ 50$ bn to over US $\$ 200$ bn during the period. During the 2008 financial crisis, Brazilian real substantially depreciated, stimulating inflation to almost reach the upper bound. Reserves fell during this period. It is only after mid-2009 when the sample period starts that the exchange-rate and reserve stocks again began an upward trend.
} 
investment. In this case, competing countries might accumulate reserves in attempt to lure international productive capital vis-à-vis their neighbours.

This paper empirically investigates the mercantilist motive hypothesis and the dynamics of cross-country reserve accumulation using a suite of latent factor models. Section 1 first summarizes the data used to examine the hypotheses of the paper. Sections 2 and 3 specify the empirical model and estimation method. The empirical results are contained in Sections 4 and 5. Section 4 is a test of the link between reserve fluctuations measured directly through changes in Brazilian intervention and exchange rate returns in Brazil as well as the consequent intervention spillover effects into the currency returns of neighbouring countries. Given our daily data on intervention, it is known exactly when intervention occurs and, like Fry-McKibbin and Wanaguru (2013), this information is used in the identification of the model. The same model is then reestimated using Brazilian reserves rather than the intervention data. As usually intervention data is no readily obtainable, the ability of the model to uncover the importance of intervention in currency markets using reserve changes rather than intervention is assessed. The model of spillovers across regional reserves markets is undertaken in Section 5, followed by concluding comments in Section 6 .

\section{Data}

This section presents the Brazilian data on the currency market, intervention and reserves, followed by data on the neighbouring markets and finishes with a discussion of the data used to control for the global environment. The data set is chosen to test the four hypotheses of this paper. The first hypothesis is a test of the effectiveness of Brazil's currency intervention and the mercantilist motive hypothesis from the perspective of the currency market of Brazil. Second is a test of the spillovers from Brazil to the currency markets of neighbouring countries focussing first on Argentina, and then on Chile and Peru. Third is the ability of the model to recover the effects of intervention detected in the first and second hypotheses using data on Brazilian foreign reserves, rather than the direct intervention data (which for many countries is unavailable). Finally, the extent of the intervention spillover effects on regional reserves is evaluated.

The data set to test the first and second hypotheses is labeled Model A1 and consists of a vector $\left(Y_{t}\right)$ of six variables including four exchange rate returns, one neighbouring 
country reserve change variable and Brazilian currency intervention,

$$
\text { Model A1 : } Y_{t}=\left[E U R_{t}, G B P_{t}, A R S_{t}, \text { Ares }_{t}, B R L_{t}, \text { Bint }_{t}\right]^{\prime} \text {, }
$$

where $E U R_{t}$ and $G B P_{t}$ are the currency returns of the euro and British pound, $A R S_{t}$ and Arest $_{t}$ are the Argentine peso currency returns and change in reserves, and $B R L_{t}$ and Bint $_{t}$ are the Brazilian real currency returns and the intervention data. The data set to test the third hypothesis is labelled Model B1. This data set is similar to that for model A1 except that the intervention data for Brazil is substituted with Brazilian reserve changes $\left(\right.$ Bres $\left._{t}\right)$ where now $Y_{t}$ is

$$
\text { Model B1 : } Y_{t}=\left[E U R_{t}, G B P_{t}, A R S_{t}, \text { Ares }_{t}, B R L_{t}, \text { Bres }_{t}\right]^{\prime} .
$$

The exchange rates in the model are expressed in terms of local currency per US dollar so that an increase (decrease) indicates a depreciation (appreciation) of the local currency. The exchange rate returns are computed by taking the first difference of the natural logarithm of the exchange rates and are multiplied by 100 to express the data in percentage terms. The change in reserves for each country are the first-difference of reserve stocks in USD millions. The Brazilian foreign exchange market intervention data $\left(\right.$ Bint $\left._{t}\right)$ represents the daily net open-market operations of the Central Bank of Brazil in the domestic foreign exchange market. The sample period extends from May 4, 2009 to June 29, 2012. The sample consists of a total of $T=825$ observations. In the empirical application all data are standardized.

Figure 2 plots the data related to the exchange rate, currency intervention and reserves in Brazil. The left panel of the figure shows the percentage Brazilian real returns against the US dollar, and the right panel shows the currency intervention data versus changes in Brazilian foreign exchange reserves. Positive values of the intervention data are net purchases of US dollars; whereas negative values are net sales. In theory, a central bank can influence the volatility and level of the exchange rate by exercising open-market operations. Ceteris paribus, a sizable net purchase (sale) of US dollars should lead to a depreciation (appreciation) of the domestic currency against the US dollar. There is a close accounting relationship between central bank currency intervention and reserves. All else being equal, every dollar acquired through central bank currency intervention through purchases will increase the reserve stock by one dollar. Notwithstanding, reserve stocks can also vary due to other operations, such as external debt amortization and interest-rate services. In Brazil, a large proportion 
Figure 2a:

Brazil's Exchange Rate Returns (BRL/US\$), in percent.

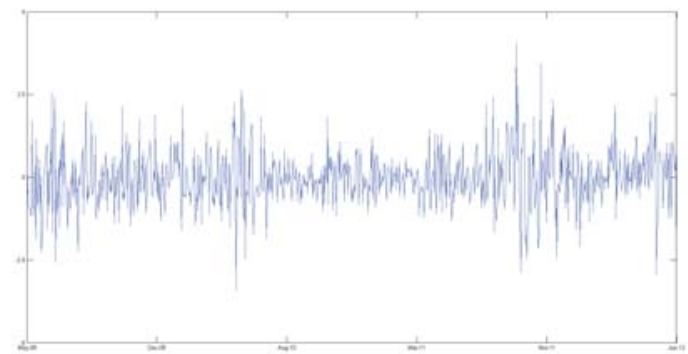

Figure 2b:

Brazil's Currency Intervention, US\$bn (left axis, dashed line) vs. Reserve Changes, US\$bn (right axis, solid line).

Source: Central Bank of Brazil.

of the reserve changes appear to be due to central bank currency intervention, with a correlation coefficient between these two variables of 0.69 . No role for sterilization is included in the model.

Descriptive statistics on the variables in the models are contained in Table 1 . The daily reserve changes and the currency intervention data for Brazil in the figure shows that Brazil intervened on 585 out of 825 days. Apart from net sales of US $\$ 924$ million on May 7 and US\$624 million on June 5 in 2009, all of the other days on which the central bank intervene consist of net purchases of US dollars indicating the mercantilist policy preference of the central bank. Intervention through purchases cumulate to US $\$ 145.5 b n$ over the period with Brazil's reserve stock rising accordingly by US\$183.4bn, from US\$190.5bn in May 2009 to US\$373.9bn in June 2012. The table of statistics also shows that Brazilian currency returns are most volatile with a standard deviation of 0.8035 , while reserve stock changes are also largest in magnitude compared to the other Latin American countries.

The second hypothesis of this paper is the possibility that central bank foreign exchange operations in one country can influence exchange rates in neighbouring economies. For example, Brazil is by far Argentina's biggest trade partner, accounting for onequarter of the Argentine total external trade. Given this magnitude, it is reasonable to suspect that, for its relative economic size, proximity and trade links, Brazil's currency intervention should impact on Argentina's exchange rate market. On the other 
Table 1: Descriptive Statistics

Source: DATASTREAM; Central Bank of Brazil (BACEN); Authors' calculations.

\begin{tabular}{lrrrrr}
\hline \hline Variables & Mean & Median & Max & Min & Std Dev \\
\hline Exchange rate returns (\%) & & & & & \\
BRL & -0.009 & -0.026 & 4.026 & -3.608 & 0.804 \\
ARS & 0.024 & 0.005 & 1.381 & -0.817 & 0.124 \\
CLP & -0.018 & 0.000 & 4.632 & -2.218 & 0.681 \\
PEN & -0.014 & -0.018 & 1.722 & -1.242 & 0.248 \\
EUR & 0.005 & 0.000 & 2.105 & -2.307 & 0.674 \\
GBP & -0.007 & 0.007 & 2.160 & -2.072 & 0.616 \\
& & & & & \\
Foreign Reserve Changes (US\$mil) & & & & & \\
Bres & 222.3 & 157.0 & 5279.0 & -1404.0 & 508.1 \\
Ares & 0.0 & 6.1 & 503.0 & -1871.0 & 141.6 \\
Cres & 20.3 & 0.0 & 2399.5 & -1990.2 & 355.9 \\
Pres & 31.7 & 5.0 & 2819.9 & -957.1 & 220.5 \\
Brazil's currency intervention (US\$mil) & & & & & \\
Bint & 174.4 & 65.1 & $4,897.0$ & -923.7 & 343.7 \\
& & & & & \\
\hline
\end{tabular}

hand, Argentinean intervention is less likely to have an effect on Brazil, with Brazil's major trade partners including the European Union (21.7\%), China (14.9\%), the US $(12.5 \%)$ and Argentina (8.7\%). ${ }^{4}$ At the beginning of the sample period in May 2009, Argentina and Brazil held the highest reserve stock levels in South America, respectively of US\$46bn and US\$190bn.

In the robustness analysis of the paper, the hypothesis of central bank foreign exchange operations in one country affecting smaller economies is reexamined by respectively replacing the data for Argentina with data for Chile and Peru. ${ }^{5}$ Brazil is the 5th largest trading partner of both Chile and Peru, accounting for $7.2 \%$ and $5.2 \%$ of their total external trade respectively. Conversely, Chile and Peru rank 7th and 24th as Brazil's major trade partners, accounting for $2.2 \%$ and $0.8 \%$ of Brazil's external trade, respectively. ${ }^{6}$

To control for the global currency market two major non-Latin American markets

\footnotetext{
${ }^{4}$ Measured in total external trade, that is, the sum of exports and imports. Source: IMF Direction of Trade Statistics, 2010.

${ }^{5}$ See Figures 3 in the Appendix for data on Brazil and its neighbouring countries Argentina, Chile and Peru with respect to: exchange rate levels, exchange rate returns, foreign reserve stock levels, and foreign reserve stock changes.

${ }^{6}$ Source: IMF Direction of Trade Statistics, 2010.
} 
are included in the data set with Brazil and the neighbouring economies. These are the euro and the British pound. The inclusion of the euro covers Brazil's major trading partner and the pound is one of the world's most traded currency. ${ }^{7}$ The combination of foreign exchange rates in the model captures potential geopolitical differences between developed and emerging economies in South America - and more specifically to the common market of MERCOSUR, of which Argentina and Brazil are key members, as well as more general developed country currency movements coming from the European region. It is assumed that Brazil's currency interventions cannot have a significant impact on the British pound and euro currency markets: (1) Brazil is geographically far from Europe; (2) Brazil's currency is not globally traded; and (3) Brazil plays a relatively small part in world trade, accounting for less than $3 \%$ of Europe's external trade.

The final hypothesis examining Brazilian intervention on regional reserve stocks uses the reserves data for Argentina, Chile, Peru and Brazil above. Formally, the selection of the reserve series for use in the final model follow the criteria of: data availability, as few countries publicise their reserve stocks on a daily basis; regional links, the sample is concentrated in South America with substantial trade links with Brazil; and reserves volume, Brazil, Argentina, Peru and Chile lead the South American countries in this dimension and in this order in terms of the ranking of reserve stocks in 2009.

Brazil's reserves stocks are the highest throughout the sample, starting at US\$190.5bn and finishing at US\$373.9bn. Argentina's reserves are the second highest in the sample, at US\$46.4bn, and reach a maximum of US\$52.7bn in the beginning of 2011 before finishing in June 2012 at the same level that it started in 2009. Chile's reserves are the lowest of all four country stocks, although doubling during the sample period, from US $\$ 23.6 \mathrm{bn}$ to US\$40.3bn. Peru's reserve stocks started at US\$31.1bn and steadily increased to US\$57.2bn in June 2012, overtaking Argentina's second place in the sample. ${ }^{8}$

\section{Model Specification}

To examine the key drivers of currency returns, reserves and intervention for the two data sets described above, a latent factor model is specified using a similar framework to Fry-McKibbin and Wanaguru (2013). The data set $Y_{t}$ is specified as a function

\footnotetext{
${ }^{7}$ Although being Brazil's second largest trading partner, the Chinese yuan is excluded due to China's fixed exchange rate.

${ }^{8}$ See Figures 3 in the Appendix.
} 
of a set of orthogonal latent factors $f=\left\{\omega, \kappa, \kappa^{L A}, b r, u\right\}$, which comprise: a global factor $\left(\omega_{t}\right)$ common to all variables; a currency factor $\left(\kappa_{t}\right)$ common to the exchange rate returns; a currency factor $\left(\kappa_{t}^{L A}\right)$ common only to the exchange rate returns of the Latin American countries; a Brazilian market factor $\left(b r_{t}\right)$; and, lastly, an idiosyncratic (or residual) factor $\left(u_{t}\right)$ capturing the idiosyncrasies of each separate market including the intervention market.

Following Fry-McKibbin and Wanaguru (2013), the distinction in the data where it is known on which days intervention took place is used to identify the model and to isolate the contribution of Brazil's central bank currency intervention on the exchange rate markets of Argentina and Brazil. The model assumes the dynamics of the currency returns and reserves markets differ on intervention days $(j=1)$ compared to nonintervention days $(j=0)$, which probably prompted the intervention action in the first place. The non-intervention day component of the model is nested in the intervention day model specification.

Model A1 for example is expressed as

$$
Y_{t}^{j}=\Lambda^{j} F_{t}
$$

on non-intervention days $(j=0)$ where

$$
\begin{aligned}
{\left[\begin{array}{c}
E U R_{t}^{0} \\
G B P_{t}^{0} \\
A R S_{t}^{0} \\
A r e s_{t}^{0} \\
B R L_{t}^{0} \\
B i n t_{t}^{0}
\end{array}\right]=\left[\begin{array}{c}
\lambda_{1, \omega}^{0} \\
\lambda_{2, \omega}^{0} \\
\lambda_{3, \omega}^{0} \\
\lambda_{,, \omega}^{0} \\
\lambda_{5, \omega}^{0} \\
\lambda_{6, \omega}^{0}
\end{array}\right] \omega_{t}+\left[\begin{array}{c}
\lambda_{1, \kappa}^{0} \\
\lambda_{2, \kappa}^{0} \\
\lambda_{3, \kappa}^{0} \\
0 \\
\lambda_{5, \kappa}^{0} \\
0
\end{array}\right] \kappa_{t}+\left[\begin{array}{c}
0 \\
0 \\
\lambda_{3, \kappa^{L A}}^{0} \\
0 \\
\lambda_{5, \kappa^{L A}}^{0} \\
0
\end{array}\right] \kappa_{t}^{L A}+\left[\begin{array}{c}
0 \\
0 \\
0 \\
0 \\
\lambda_{5, b r}^{0} \\
\lambda_{6, b r}^{0}
\end{array}\right] b r_{t} } \\
+ \\
+\left[\begin{array}{cccccc}
\lambda_{1, u}^{0} & 0 & 0 & 0 & 0 & 0 \\
0 & \lambda_{2, u}^{0} & 0 & 0 & 0 & 0 \\
0 & 0 & \lambda_{3, u}^{0} & 0 & 0 & 0 \\
0 & 0 & 0 & \lambda_{4, u}^{0} & 0 & 0 \\
0 & 0 & 0 & 0 & \lambda_{5, u}^{0} & 0 \\
0 & 0 & 0 & 0 & 0 & \lambda_{6, u}^{0}
\end{array}\right]\left[\begin{array}{l}
u_{1, t} \\
u_{2, t} \\
u_{3, t} \\
u_{4, t} \\
u_{5, t} \\
u_{6, t}
\end{array}\right] .
\end{aligned}
$$

The same basic structure exists on intervention days $(j=1)$, but with structural 
breaks allowed on all parameters except for on the Brazilian market factor ${ }^{9}$

$$
\begin{aligned}
& {\left[\begin{array}{c}
E U R_{t}^{1} \\
G B P_{t}^{1} \\
A R S_{t}^{1} \\
\text { Ares }_{t}^{1} \\
B R L_{t}^{1} \\
\text { Bint }_{t}^{0}
\end{array}\right]=\left[\begin{array}{c}
\left(\lambda_{1, \omega}^{0}+\lambda_{1, \omega}^{1}\right) \\
\left(\lambda_{2, \omega}^{0}+\lambda_{2, \omega}^{1}\right) \\
\left(\lambda_{3, \omega}^{0}+\lambda_{3, \omega}^{1}\right) \\
\left(\lambda_{4, \omega}^{0}+\lambda_{4, \omega}^{1}\right) \\
\left(\lambda_{5, \omega}^{0}+\lambda_{5, \omega}^{1}\right) \\
\left(\lambda_{6, \omega}^{0}+\lambda_{6, \omega}^{1}\right)
\end{array}\right] \omega_{t}+\left[\begin{array}{c}
\left(\lambda_{1, \kappa}^{0}+\lambda_{1, \kappa}^{1}\right) \\
\left(\lambda_{2, \kappa}^{0}+\lambda_{2, \kappa}^{1}\right) \\
\left(\lambda_{3, \kappa}^{0}+\lambda_{3, \kappa}^{1}\right) \\
0 \\
\left(\lambda_{5, \kappa}^{0}+\lambda_{5, \kappa}^{1}\right) \\
0
\end{array}\right] \kappa_{t}+\left[\begin{array}{c}
0 \\
0 \\
\left.\left(\lambda_{3, \kappa}^{0}\right)+\lambda_{3, \kappa}^{1}\right) \\
0 \\
\left(\lambda_{5, \kappa}^{0}{ }^{L A}+\lambda_{5, \kappa}^{1}\right) \\
0
\end{array}\right] \kappa_{t}^{L A}+\left[\begin{array}{c}
0 \\
0 \\
0 \\
0 \\
\lambda_{5, b r}^{0} \\
\lambda_{6, b r}^{0}
\end{array}\right] b r_{t}} \\
& +\left[\begin{array}{cccccc}
\left(\lambda_{1, u}^{0}+\lambda_{1, u}^{1}\right) & 0 & 0 & 0 & 0 & 0 \\
0 & \left(\lambda_{2, u}^{0}+\lambda_{2, u}^{1}\right) & 0 & 0 & 0 & 0 \\
0 & 0 & \left(\lambda_{3, u}^{0}+\lambda_{3, u}^{1}\right) & 0 & 0 & \iota_{a r} \\
0 & 0 & 0 & \left(\lambda_{4, u}^{0}+\lambda_{4, u}^{1}\right) & 0 & 0 \\
0 & 0 & 0 & 0 & \left(\lambda_{5, u}^{0}+\lambda_{5, u}^{1}\right) & \iota_{b r} \\
0 & 0 & 0 & 0 & 0 & \left(\lambda_{6, u}^{0}+\lambda_{6, u}^{1}\right)
\end{array}\right]\left[\begin{array}{c}
u_{1, t} \\
u_{2, t} \\
u_{3, t} \\
u_{4, t} \\
u_{5, t} \\
u_{6, t}
\end{array}\right] \text {. }
\end{aligned}
$$

On the intervention days, there are also two extra loading parameters, $\iota_{a r}$ and $\iota_{b r}$ in addition to those when $j=0$. These parameters are designed to test the impact of Brazil's central bank currency intervention on the exchange rate returns of Argentina and Brazil as well as to make the Argentinean and Brazilian currency returns a function of the idiosyncratic movements in the Brazilian intervention market on intervention days. On intervention days this factor is referred to as an 'intervention factor'. In line with the literature, the parameter $\iota_{b r}$ is the raison-d'être of Brazil's currency intervention, where central banks operate in the foreign exchange market to intervene in its own exchange rate path (Menkhoff, 2012). The capacity of Brazil's central bank to affect the Argentine currency returns through spillovers from its own intervention is governed by parameter $\left(\iota_{a r}\right)$. A test of the hypothesis $\iota_{b r}=0$ is a test that intervention in Brazil is ineffective. A test of the hypothesis $\iota_{a r}=0$ is a test that intervention in Brazil does not affect the Argentinean currency market.

Model B1 is specified in the same way as Model A1 but with the data Bint $t_{t}^{j}$ replaced by $\operatorname{Bres}_{t}^{j}$. The notation for the factor loadings is $\lambda_{i, f}^{j}$, where: $j=\{0,1\}$ accounts for possible structural breaks in the factor structures on intervention days $(j=1)$ in comparison to non-interventions days $(j=0)$ for each of the $i=\{1,2, \ldots, 6\}$ variables, and $f=\left\{\omega, \kappa, \kappa^{L A}, b r, u\right\}$ denotes the corresponding orthogonal latent factor to which each parameter is assigned.

\footnotetext{
${ }^{9}$ There are two reasons for not allowing a structural break in the Brazilian market factor: First, it allows a proper identification between intervention and non-intervention days; Second, we assume that the Brazilian market factor is the same throughout the sample.
} 
The advantage of this modelling framework is that it provides a parsimonious representation of the data without the need to identify nor to model observable variables corresponding to the global or other common factors. The factor structure also ensures that there is no endogeneity issue by including both currency and intervention data in the model.

Features of iid and unit variance assumptions in the factors $F_{t}$ enables the standardized variables in the model to be decomposed in terms of the contribution of each factor to their overall volatility. The variance of each variable in $Y_{t}$ for model A for example on the intervention days $(j=1)$ is

$$
\begin{aligned}
\operatorname{Var}\left(E U R_{t}^{1}\right)= & \left(\lambda_{1, \omega}^{0}+\lambda_{1, \omega}^{1}\right)^{2}+\left(\lambda_{1, \kappa}^{0}+\lambda_{1, \kappa}^{1}\right)^{2}+\left(\lambda_{1, u}^{0}+\lambda_{1, u}^{1}\right)^{2}, \\
\operatorname{Var}\left(G B P_{t}^{1}\right)= & \left(\lambda_{2, \omega}^{0}+\lambda_{2, \omega}^{1}\right)^{2}+\left(\lambda_{2, \kappa}^{0}+\lambda_{2, \kappa}^{1}\right)^{2}+\left(\lambda_{2, u}^{0}+\lambda_{2, u}^{1}\right)^{2}, \\
\operatorname{Var}\left(A R S_{t}^{1}\right)= & \left(\lambda_{3, \omega}^{0}+\lambda_{3, \omega}^{1}\right)^{2}+\left(\lambda_{3, \kappa}^{0}+\lambda_{3, \kappa}^{1}\right)^{2}+\left(\lambda_{3, \kappa^{L A}}^{0}+\lambda_{3, \kappa^{L A}}^{1}\right)^{2}+\iota_{a r}^{2}+\left(\lambda_{3, u}^{0}+\lambda_{3, u}^{1}\right)^{2}, \\
\operatorname{Var}\left(\text { Ares }_{t}^{1}\right)= & \left(\lambda_{4, \omega}^{0}+\lambda_{4, \omega}^{1}\right)^{2}+\left(\lambda_{4, u}^{0}+\lambda_{4, u}^{1}\right)^{2}, \\
\operatorname{Var}\left(B R L_{t}^{1}\right)= & \left(\lambda_{5, \omega}^{0}+\lambda_{5, \omega}^{1}\right)^{2}+\left(\lambda_{5, \kappa}^{0}+\lambda_{5, \kappa}^{1}\right)^{2}+\left(\lambda_{5, \kappa^{L A}}^{0}+\lambda_{5, \kappa}^{1} L A\right)^{2}+\left(\lambda_{5, b r}^{0}\right)^{2}+\iota_{b r}^{2} \\
& +\left(\lambda_{5, u}^{0}+\lambda_{5, u}^{1}\right)^{2}, \\
\operatorname{Var}\left(\operatorname{Bint}_{t}^{1}\right)= & \left(\lambda_{6, \omega}^{0}+\lambda_{6, \omega}^{1}\right)^{2}+\left(\lambda_{6, b r}^{0}\right)^{2}+\left(\lambda_{6, u}^{0}+\lambda_{6, u}^{1}\right)^{2} .
\end{aligned}
$$

The corresponding proportion of the volatility of each variable attributable to each factor is displayed in Table 2. The objective of these calculations is to provide a measure of the relative importance of each of these factors on currency and reserve markets to assess the mercantilist hypothesis in terms of the extent of intervention spillovers from Brazil, and in Model B, to assess the ability of the model to detect intervention effects using changes in reserves rather than intervention.

\section{Estimation Method}

The factor model described in Section 2 uses a Generalised Method of Moments (GMM) estimator, which produces consistent, asymptotically normal and efficient estimates 
Table 2: Volatility Decomposition on Intervention Days

Notes: To recover the variance decomposition on the non-intervention days $(j=0)$, the strutural break parameters $\left(\lambda_{i, f}^{1}, \iota_{b r}, \iota_{a r}\right)$ are suppressed.

\begin{tabular}{|c|c|c|c|c|c|c|}
\hline & & & Facto & & & \\
\hline & Global & Currency & LA-currency & Brazil & Intervention & Residual \\
\hline$E U R_{t}^{1}$ & $\frac{\left(\lambda_{1, \omega}^{0}+\lambda_{1, \omega}^{1}\right)^{2}}{\operatorname{Var}\left(E U R_{t}^{1}\right)}$ & $\frac{\left(\lambda_{1, \kappa}^{0}+\lambda_{1, \kappa}^{1}\right)^{2}}{\operatorname{Var}\left(E U R_{t}^{1}\right)}$ & 一 & - & - & $\frac{\left(\lambda_{1, u}^{0}+\lambda_{1, u}^{1}\right)^{2}}{\operatorname{Var}\left(E U R_{t}^{1}\right)}$ \\
\hline$G B P_{t}^{1}$ & $\frac{\left(\lambda_{2, \omega}^{0}+\lambda_{2, \omega}^{1}\right)^{2}}{\operatorname{Var}\left(G B P_{t}^{1}\right)}$ & $\frac{\left(\lambda_{2, \kappa}^{0}+\lambda_{2, \kappa}^{1}\right)^{2}}{\operatorname{Var}\left(G B P_{t}^{1}\right)}$ & - & - & - & $\frac{\left(\lambda_{2, u}^{0}+\lambda_{2, u}^{1}\right)^{2}}{\operatorname{Var}\left(G B P_{t}^{1}\right)}$ \\
\hline$A R S_{t}^{1}$ & $\frac{\left(\lambda_{3, \omega}^{0}+\lambda_{3, \omega}^{1}\right)^{2}}{\operatorname{Var}\left(A R S_{t}^{1}\right)}$ & $\frac{\left(\lambda_{3, \kappa}^{0}+\lambda_{3, \kappa}^{1}\right)^{2}}{\operatorname{Var}\left(A R S_{t}^{1}\right)}$ & $\frac{\left(\lambda_{3, \kappa}^{0} L A\right.}{\operatorname{Var}\left(A R \lambda_{t, \kappa}^{1}\right)}$ & - & $\frac{\iota_{a r}^{2}}{\operatorname{Var}\left(A R S_{t}^{1}\right)}$ & $\frac{\left(\lambda_{3, u}^{0}+\lambda_{3, u}^{1}\right)^{2}}{\operatorname{Var}\left(A R S_{t}^{1}\right)}$ \\
\hline $\operatorname{Ares}_{t}^{1}$ & 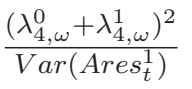 & - & - & - & - & $\frac{\left(\lambda_{4, u}^{0}+\lambda_{4, u}^{1}\right)^{2}}{\operatorname{Var}\left(\operatorname{Ares}_{t}^{1}\right)}$ \\
\hline$B R L_{t}^{1}$ & $\frac{\left(\lambda_{5, \omega}^{0}+\lambda_{5, \omega}^{1}\right)^{2}}{\operatorname{Var}\left(B R L_{t}^{1}\right)}$ & $\frac{\left(\lambda_{5, \kappa}^{0}+\lambda_{5, \kappa}^{1}\right)^{2}}{\operatorname{Var}\left(B R L_{t}^{1}\right)}$ & 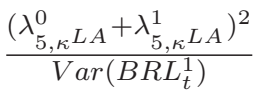 & $\frac{\left(\lambda_{5, b r}^{0}\right)^{2}}{\operatorname{Var}\left(B R L_{t}^{1}\right)}$ & $\frac{\iota_{b r}^{2}}{\operatorname{Var}\left(B R L_{t}^{1}\right)}$ & $\frac{\left(\lambda_{5, u}^{0}+\lambda_{5, u}^{1}\right)^{2}}{\operatorname{Var}\left(B R L_{t}^{1}\right)}$ \\
\hline Bint $_{t}^{1}$ & $\frac{\left(\lambda_{6, \omega}^{0}+\lambda_{6, \omega}^{1}\right)^{2}}{\operatorname{Var}\left(\operatorname{Bint}_{t}^{1}\right)}$ & - & - & $\frac{\left(\lambda_{6, b r}^{0}\right)^{2}}{\operatorname{Var}\left(\operatorname{Bint}_{t}^{1}\right)}$ & - & $\frac{\left(\lambda_{6, u}^{0}+\lambda_{6, u}^{1}\right)^{2}}{\operatorname{Var}\left(\operatorname{Bint}_{t}^{1}\right)}$ \\
\hline
\end{tabular}

(Hansen, 1982). GMM estimation focuses on using information contained in the moments of the data. The goal is to compute the unknown model parameters by matching the theoretical moments of the model to the empirical moments of the data in both the intervention-day and non-intervention-day data sets.

The identification and estimation of the model make use of the precise known days of currency intervention in the Brazilian foreign exchange market. ${ }^{10}$ In this scenario, both Model A1 and Model B1 are overidentified. Dividing the data into the non-intervention and intervention days provides $((6 \times 7) / 2)=21$ empirical moments calculated using the non-intervention data, and the same number of empirical moments calculated using the intervention data. This gives a total of 42 empirical moments to estimate the 40 unknown parameters of the model (where 20 parameters are specified for the nointervention days, and 20 parameters are specified for the intervention days).

Let $H^{j}$ be a $T^{j}$-by-21 empirical matrix containing the contemporaneous crossproducts between the 6 standardized variables in $Y_{t}^{j}$, and where $T^{j}$ is the number of daily observations in each data set $j=\{0,1\}$. $H^{j}$ is

\footnotetext{
${ }^{10}$ For similar strategy, see Fry-McKibbin and Wanaguru (2013) and Dungey et al. (2010).
} 


$$
H^{j}=\left[\begin{array}{ccccccccc}
Y_{1,1}^{j} Y_{1,1}^{j} & \ldots & Y_{6,1}^{j} Y_{6,1}^{j} & Y_{1,1}^{j} Y_{2,1}^{j} & \ldots & Y_{1,1}^{j} Y_{6,1}^{j} & Y_{2,1}^{j} Y_{3,1}^{j} & \ldots & Y_{5,1}^{j} Y_{6,1}^{j} \\
Y_{1,2}^{j} Y_{1,2}^{j} & \ldots & Y_{6,2}^{j} Y_{6,2}^{j} & Y_{1,2}^{j} Y_{2,2}^{j} & \ldots & Y_{1,2}^{j} Y_{6,2}^{j} & Y_{2,2}^{j} Y_{3,2}^{j} & \ldots & Y_{5,2}^{j} Y_{6,2}^{j} \\
\vdots & \vdots & \vdots & \vdots & \vdots & \vdots & \vdots & \vdots & \vdots \\
Y_{1, T^{j}}^{j} Y_{1, T^{j}}^{j} & \ldots & Y_{6, T^{j}}^{j} Y_{6, T^{j}}^{j} & Y_{1, T^{j}}^{j} Y_{2, T^{j}}^{j} & \ldots & Y_{1, T^{j}}^{j} Y_{6, T^{j}}^{j} & Y_{2, T^{j}}^{j} Y_{3, T^{j}}^{j} & \ldots & Y_{5, T^{j}}^{j} Y_{6, T^{j}}^{j}
\end{array}\right]
$$

for $j=\{0,1\}$.

It is straightforward to see that by the law of large numbers the average value of each column of $H^{j}$ asymptotically converges to the respective true second-order expectation $E\left(Y_{i, t}^{j}, Y_{j, t}^{j}\right)$ for $i, j=\{1,2,3,4,5,6\} .{ }^{11}$ In this case, an optimization problem is solved by finding the parameter values in $\Lambda^{j}$ of eq. (1) that minimizes the difference between the empirical moments extracted from the columns of $H^{j}$ and the theoretical moments derived from the lower diagonal entries of $\Lambda^{j} \Lambda^{j^{\prime}}$

$$
\Lambda^{j} \Lambda^{j^{\prime}}=\left[\begin{array}{llllll}
E\left(Y_{1, t}^{j} Y_{1, t}^{j}\right) & & & & & \\
E\left(Y_{1, t}^{j} Y_{2, t}^{j}\right) & E\left(Y_{2, t}^{j} Y_{2, t}^{j}\right) & & & \\
E\left(Y_{1, t}^{j} Y_{3, t}^{j}\right) & E\left(Y_{2, t}^{j} Y_{3, t}^{j}\right) & E\left(Y_{3, t}^{j} Y_{3, t}^{j}\right) & & \\
E\left(Y_{1, t}^{j} Y_{4, t}^{j}\right) & E\left(Y_{2, t}^{j} Y_{4, t}^{j}\right) & E\left(Y_{3, t}^{j} Y_{4, t}^{j}\right) & E\left(Y_{4, t}^{j} Y_{4, t}^{j}\right) & & \\
E\left(Y_{1, t}^{j} Y_{5, t}^{j}\right) & E\left(Y_{2, t}^{j} Y_{5, t}^{j}\right) & E\left(Y_{3, t}^{j} Y_{5, t}^{j}\right) & E\left(Y_{4, t}^{j} Y_{5, t}^{j}\right) & E\left(Y_{5, t}^{j} Y_{5, t}^{j}\right) & \\
E\left(Y_{1, t}^{j} Y_{6, t}^{j}\right) & E\left(Y_{2, t}^{j} Y_{6, t}^{j}\right) & E\left(Y_{3, t}^{j} Y_{6, t}^{j}\right) & E\left(Y_{4, t}^{j} Y_{6, t}^{j}\right) & E\left(Y_{5, t}^{j} Y_{6, t}^{j}\right) & E\left(Y_{6, t}^{j} Y_{6, t}^{j}\right)
\end{array}\right] .
$$

Lastly, in order to calculate the standard errors of the parameter estimates, a bootstrap procedure (Efron and Tibshirani, 1994) separately resamples both data sets $(j=\{0,1\})$ 1000 times.

\section{Brazilian Reserve Accumulation}

This section examines the effects of Brazil's mercantilism expressed through central bank currency intervention on the returns of the Brazilian and Argentine currencies in accordance with eq. (1). Section 4.1 presents the results for Model A1 (using Brazil's central bank currency intervention data). Section 4.2 analyses the results for Model B1 (using Brazil's reserve changes as a proxy for currency intervention data) and compares

\footnotetext{
${ }^{11}$ For clarity, the notation in the benchmark model is: $Y_{1, t}^{j} \equiv E U R_{t}^{j}, Y_{2, t}^{j} \equiv G B P_{t}^{j}, Y_{3, t}^{j} \equiv A R S_{t}^{j}$, $Y_{4, t}^{j} \equiv \operatorname{Ares}_{t}^{j}, Y_{5, t}^{j} \equiv B R L_{t}^{j}$ and $Y_{6, t}^{j} \equiv \operatorname{Bint}_{t}^{j}$ (Model A) or Bres ${ }_{t}^{j}$ (Model B).
} 
it with the ones in Model A1. Lastly, Section 4.3 reestimates and discusses the results for Models in the class of A and B using Chile and Peru as the neighbouring countries.

\subsection{Effects of Intervention on Brazil and Argentina}

The volatility decomposition of the model of central bank intervention (Model A1) is presented in Table 3. Recapping, the contributing factors for the currency returns and reserve changes are: 'global' which is common to all variables; 'currency' which is common to all exchange rate returns; 'LA-currency' which is common to the Latin American currency markets; 'Brazil' which captures domestic factors in Brazil; 'intervention', which is the impact of Brazil's central bank intervention on the Argentine and Brazilian currency markets; ${ }^{12}$ and 'residual', which captures the idiosyncrasies of each market not accounted for by the common factors.

The top panel of Table 3 provides the percentage contribution of the latent factors for the days with no central bank currency intervention in Brazil. The currency factor dominates the volatility of the euro and British pound returns on non-intervention days, accounting for $64.35 \%$ and $53.15 \%$ respectively. In turn, the currency factor share of Brazilian currency returns is a not dissimilar 32.99\%, whereas Argentina's is small at $2.49 \%$. Indeed, Argentina's currency volatility is mostly due to common regional currency movements $(45.44 \%)$ and domestic factors $(47.47 \%)$. As expected, on the non-intervention days, the intervention variable responds only to itself, consistent with the model for Sri Lanka in Fry-McKibbin and Wanaguru (2013).

The bottom panel of Table 3 presents the volatility decomposition on the days of intervention by the Brazilian central bank. Wald tests on the joint significance of the intervention parameters confirm the validity of the model, including the structural breaks imposed on intervention days (a test of $H_{0}: \iota_{b r}=\iota_{a r}=\lambda_{i, f}^{1}=0$ ) as shown in Table 4. Intervention accounts substantially towards explaining the variability of currency returns in Brazil, with almost $53 \%$ due to the intervention factor. ${ }^{13}$ Indeed, on days of intervention, there is no contribution of the idiosyncratic factor to the Brazilian

\footnotetext{
${ }^{12}$ The intervention factor is derived from the impact of the idiosyncratic factor of Brazil's central bank intervention $\left(u_{6, t}\right)$ into the currency markets of Brazil and Argentina through the respective parameters $\iota_{b r}$ and $\iota_{a r}-$ see eq. (1).

${ }^{13}$ This is much more substantial than for the case of Sri Lanka which is around $6 \%$ of volatility, although it is clear that the Sri Lankan Central Bank objectives are much different to those of Brazil, with the intervention data split fairly evenly between purchases and sales compared to the Brazilian case of almost exclusively purchases. That is, the Brazilian central bank appears to be operating the Mercantalist motive more forcefully than the Sri Lankan central bank is also concerned with containing exchange rate volatility.
} 
Table 3: Volatility Decomposition for Factor Model A1

Notes: Contribution of each factor to total volatility, in percent. The model is estimated over the period May 4, 2009-June 29, 2012 (see eq.(1) and Table 2).

\begin{tabular}{|c|c|c|c|c|c|c|c|}
\hline & \multicolumn{6}{|c|}{ Factors } & \multirow[b]{2}{*}{ Total } \\
\hline & Global & Currency & LA-currency & Brazil & Intervention & Residual & \\
\hline \multicolumn{8}{|c|}{ Non-intervention days $(j=0)$} \\
\hline$E U R_{t}^{0}$ & 12.45 & 64.35 & - & - & - & 23.20 & 100.0 \\
\hline$G B P_{t}^{0}$ & 11.84 & 53.15 & - & - & - & 35.01 & 100.0 \\
\hline$A R S_{t}^{0}$ & 4.59 & 2.49 & 45.44 & - & - & 47.47 & 100.0 \\
\hline $\operatorname{Ares}_{t}^{0}$ & 29.84 & - & - & - & - & 70.16 & 100.0 \\
\hline$B R L_{t}^{0}$ & 13.04 & 32.99 & 0.27 & 0.24 & - & 53.46 & 100.0 \\
\hline $\operatorname{Bint}_{t}^{0}$ & 1.26 & - & - & 1.25 & - & 97.49 & 100.0 \\
\hline \multicolumn{8}{|c|}{ Intervention days $(j=1)$} \\
\hline$E U R_{t}^{1}$ & 62.92 & 37.08 & - & - & - & 23.20 & 100.0 \\
\hline$G B P_{t}^{1}$ & 46.01 & 2.58 & - & - & - & 51.41 & 100.0 \\
\hline$A R S_{t}^{1}$ & 0.15 & 2.46 & 57.09 & - & 2.79 & 37.51 & 100.0 \\
\hline $\operatorname{Ares}_{t}^{1}$ & 0.80 & - & - & - & - & 99.20 & 100.0 \\
\hline$B R L_{t}^{1}$ & 46.81 & 0.07 & 0.01 & 0.35 & 52.76 & 0.00 & 100.0 \\
\hline $\operatorname{Bint}_{t}^{1}$ & 44.86 & - & - & 0.37 & - & 54.77 & 100.0 \\
\hline
\end{tabular}

Table 4: Wald Tests on Intervention and Structural Breaks in Factor Model A1

Notes: A bootstrap procedure (resampling 1000 times) is used to calculate the variancecovariance matrix of the parameters. The model is estimated over the period May 4, 2009June 29, 2012 (see eq.(1) and Table 2). DOF denotes degrees of freedom.

\begin{tabular}{cccc}
\hline \hline Intervention Parameter & Estimate & Standard Deviation & p-value \\
\hline$\iota_{b r}$ & -0.681 & 0.112 & 0.00 \\
$\iota_{a r}$ & -0.170 & 0.071 & 0.01 \\
\hline Wald Test Hypothesis & DOF & Test Statistic & p-value \\
\hline Joint intervention parameters & & & \\
$H_{0}: \iota_{b r}=\iota_{a r}=0$ & 2 & 36.93 & 0.00 \\
$H_{0}: \iota_{b r}=\iota_{a r}=\lambda_{6, u}^{1}=0$ & 3 & 43.40 & 0.00 \\
\hline Joint structural break parameters & & & \\
$H_{0}: \iota_{b r}=\iota_{a r}=\lambda_{i, f}^{1}=0$ & 20 & 239.91 & 0.00 \\
\hline
\end{tabular}


exchange rate returns (at $0.00 \%$ ), while its corresponding estimates $\left(\lambda_{5, u}^{0}, \lambda_{5, u}^{1}\right)$ are statistically not different to zero. ${ }^{14}$

It is also worth noting that the idiosyncratic factor for the intervention variable $\left(u_{6, t}\right)$ on intervention days has basically the same impact on the overall volatility of both the intervention data and Brazilian currency returns of $52.76 \%$ and $54.77 \%$, respectively, indicating the full transfer of Brazil's central bank intervention into its currency market. The influence of the global factor changes substantially on these days, impacting all markets apart from the globally insulated Argentina. It is evident that global events in currency markets are the second major driver of the decision for Brazil to intervene. The global factor accounts for $46.81 \%$ and $44.86 \%$ of the volatility in Brazil's exchange rate returns and central bank currency intervention data on intervention days, respectively. This is in comparison to the global factor on nonintervention days when it constitutes only $13 \%$ of the volatility of the Brazilian real. The country factor for Brazil $\left(b r_{t}\right)$ does not play an important role on intervention days for either its exchange rate or intervention series, explaining less than $1 \%$ of the volatility in each Brazilian market respectively. ${ }^{15}$

After controlling for global, currency and national factors, the impact of Brazil's central bank intervention on Argentina is not large in magnitude. The intervention spillovers from Brazil to Argentina account for $2.79 \%$ of the overall volatility in Argentina's exchange rate return highlighting some cross-border effects of Brazil's central bank intervention on the neighbouring economy. In economic terms the effects of Brazilian intervention on Argentina is small in magnitude. Nonetheless Table 4 shows that the intervention parameter $\iota_{a r}$ is significant at the $1 \%$ level of significance.

\subsection{Reserve Changes as a Proxy for Intervention}

The results for the estimation of Model B1 which replaces Brazilian central bank intervention data with the proxy for intervention of reserve changes in Brazil are contained in Table 5. Notwithstanding some differences in the relative contributions of the factors which are discussed below, the volatility decomposition for Model B1 on intervention days shown in the lower panel of the table mimics the qualitative results of Model A1 for the effects of intervention on Brazil and Argentina.

\footnotetext{
${ }^{14}$ For full list of parameter estimates and p-values, see Table 17 in the Appendix.

${ }^{15}$ Earlier specifications of this model were not able to find a common Argentine factor for the currency and reserves markets and was omitted from the final model specification.
} 
Table 5: Volatility Decomposition for Factor Model B1

Notes: Contribution of each factor to total volatility, in percent. The model is estimated over the period May 4, 2009-June 29, 2012 (see eq.(1) and Table 2).

\begin{tabular}{|c|c|c|c|c|c|c|c|}
\hline & \multicolumn{6}{|c|}{ Factors } & \multirow[b]{2}{*}{ Total } \\
\hline & Global & Currency & LA-currency & Brazil & Intervention & Residual & \\
\hline \multicolumn{8}{|c|}{ Non-intervention days $(j=0)$} \\
\hline$E U R_{t}^{0}$ & 43.97 & 36.00 & - & - & - & 20.03 & 100.0 \\
\hline$G B P_{t}^{0}$ & 41.77 & 21.42 & - & - & - & 36.81 & 100.0 \\
\hline$A R S_{t}^{0}$ & 0.35 & 2.53 & 88.95 & - & - & 8.17 & 100.0 \\
\hline$A r e s_{t}^{0}$ & 8.88 & - & - & - & - & 91.12 & 100.0 \\
\hline$B R L_{t}^{0}$ & 44.10 & 6.05 & 0.26 & 5.29 & - & 44.30 & 100.0 \\
\hline $\operatorname{Bres}_{t}^{0}$ & 66.41 & - & - & 8.76 & - & 24.82 & 100.0 \\
\hline \multicolumn{8}{|c|}{ Intervention days $(j=1)$} \\
\hline$E U R_{t}^{1}$ & 53.05 & 12.94 & - & - & - & 34.01 & 100.0 \\
\hline$G B P_{t}^{1}$ & 38.98 & 25.71 & - & - & - & 35.31 & 100.0 \\
\hline$A R S_{t}^{1}$ & 6.00 & 9.78 & 23.51 & - & 1.63 & 59.08 & 100.0 \\
\hline $\operatorname{Ares}_{t}^{1}$ & 0.85 & - & - & - & - & 99.15 & 100.0 \\
\hline$B R L_{t}^{1}$ & 50.05 & 0.11 & 0.13 & 7.76 & 41.96 & 0.00 & 100.0 \\
\hline Bres $_{t}^{1}$ & 52.99 & - & - & 7.09 & - & 39.92 & 100.0 \\
\hline
\end{tabular}

Table 6: Wald Tests on Intervention and Structural Breaks in Factor Model B1

Notes: A bootstrap procedure (resampling 1000 times) was used to calculate the variancecovariance matrix of the parameters. The model is estimated over the period May 4, 2009June 29, 2012 (see eq.(1) and Table 2). DOF denotes degrees of freedom.

\begin{tabular}{cccr}
\hline \hline Intervention Parameter & Estimate & Standard Deviation & p-value \\
\hline$\iota_{b r}$ & -0.608 & 0.218 & 0.00 \\
$\iota_{a r}$ & 0.130 & 0.210 & 0.27 \\
\hline Wald Test Hypothesis & DOF & Test Statistic & p-value \\
\hline Joint intervention parameters & & & \\
$H_{0}: \iota_{b r}=\iota_{a r}=0$ & 2 & 12.36 & 0.00 \\
$H_{0}: \iota_{b r}=\iota_{a r}=\lambda_{6, u}^{1}=0$ & 3 & 13.47 & 0.00 \\
\hline Joint structural break parameters & & & \\
$H_{0}: \iota_{b r}=\iota_{a r}=\lambda_{i, f}^{1}=0$ & 20 & 110.05 & 0.00 \\
\hline
\end{tabular}


The impact of central bank intervention using the reserve change data as the proxy for intervention is unequivocally consistent with the results for Model A1. Brazilian intervention contributes a substantial $41.96 \%$ to currency market volatility in Brazil when measured using the change in reserves which is not dissimilar to the $52.76 \%$ when directly measured intervention is used in Model A1 in Table 3. Both models show that there is robust evidence of a strong relationship between foreign reserve increases and intervention and the exchange rate in Brazil. Similarly, measuring intervention through reserves results in Brazilian intervention affecting the Argentinian currency market by $1.63 \%$ compared to $2.79 \%$ in the model using the direct intervention data, again confirms the qualitative result that Brazilian intervention does not strongly affect the Argentine peso returns. The intervention parameter $\iota_{b r}$ is statistically significant at the $1 \%$ level in both specifications while the parameter for the effects on Argentina $\iota_{a r}$ is not significant in the second specification (Table 4 and 6). The intervention parameters are however jointly significant in both models A1 and B1.

The differences in the factor contributions shown at the top of Table 5 compared to Table 3 for the non-intervention day data mentioned above reflect the broader nature of the reserve changes, which also occur on non-intervention days as discussed in Section 1. This explains the different weights on the non-intervention day factors when using the reserves data as in Model B1, where the intervention data is almost entirely due to the residual factor on the non-intervention days. The use of the change in reserves data rather than the intervention data results in the global factor dominating all markets apart from Argentina, including for the Brazilian reserves variable. Further, the currency factor is stronger in the euro zone; and the national Brazilian factor $b r_{t}$ shows stronger co-movements between the Brazilian exchange rate and its reserve changes; and the Latin American currency factor $\kappa^{L A}$ favours the Argentine exchange returns as opposed to the Brazilian exchange returns in both the model A1 and B1 specifications, hence acting as a de facto second residual in the volatility decomposition model for the Argentine markets.

\subsection{Robustness to Alternative Neighbouring Economies}

The hypothesis of central bank foreign exchange operations in one country affecting smaller economies is re-examined by respectively replacing the data for Argentina with data for Chile and Peru. The results presented in this subsection are produced using the same data transformations, estimation methodology and assumptions as in Sections 
1 to $3 .^{16}$ Four additional models are considered.

Models A2 and B2 replace Argentina's currency returns and reserves data with the Chilean currency returns and reserves change data consistent with Model A1, which includes intervention for Brazil $\left(\right.$ Bint $\left._{t}\right)$, so that Model A2 is

$$
\text { Model A2 : } Y_{t}=\left[E U R_{t}, G B P_{t}, C L P_{t}, C r e s_{t}, B R L_{t}, B_{i n t}\right]^{\prime} \text {, }
$$

where $C L P_{t}$ is the Chilean peso returns and $C r e s_{t}$ are Chilean reserve changes. Model $\mathrm{B} 2$, which includes the change in reserves for Brazil (Bres $s_{t}$ ) as the intervention proxy, is

$$
\text { Model B2 : } Y_{t}=\left[E U R_{t}, G B P_{t}, C L P_{t}, C r e s_{t}, B R L_{t}, B r e s_{t}\right]^{\prime} .
$$

Models A3 and B3 replace Argentina's currency returns and reserves data with the Peruvian currency returns and reserves change data consistent with Model A1, which includes intervention for Brazil $\left(\right.$ Bint $\left._{t}\right)$, so that Model A3 is

$$
\text { Model A3 : } Y_{t}=\left[E U R_{t}, G B P_{t}, P E N_{t}, \text { Pres }_{t}, B R L_{t}, \text { Bint }_{t}\right]^{\prime} \text {, }
$$

where $P E N_{t}$ is the Peruvian Nuevo Sol returns and Pres $_{t}$ are Peruvian reserve changes. Model B3, which includes the change in reserves for Brazil $\left(\right.$ Bres $\left._{t}\right)$ as the intervention proxy, is

$$
\text { Model B3 : } Y_{t}=\left[E U R_{t}, G B P_{t}, P E N_{t}, \operatorname{Pr} e s_{t}, B R L_{t}, B_{r e s}\right]^{\prime} \text {. }
$$

The Effects of Intervention on Chile and Peru The results of the estimation of the models for the effects of central bank intervention from Brazil for Chile and Peru as measured by either method are remarkably consistent with the results for Argentina in Sections 4.1 and 4.2 are contained in Tables 7 to $10 .{ }^{17}$ Replacing the intervention data with the reserves changes in Brazil as the proxy for intervention in the models for Chile and Peru also mirrors the experiment for Argentina. The volatility decompositions for the key intervention affected currencies are extremely robust, regardless the use of the

\footnotetext{
${ }^{16}$ It is desirable to estimate the model of intervention including all Latin American countries. However, in doing so, the number of variables in the data set increases to 10 variables, for a total of 110 empirical moments to estimate 66 parameters, for 44 excess moment conditions and an overidentified model (see Section 3 on the Estimation Method). In theory, this is not an impediment in itself, but after estimating such a model, two problems arose. First, the high number of degrees of freedom led to very conflicting and unstable results depending on the initial values of the GMM procedure. Second, the results failed the overidentification test, implying that the assumption of the ortogonality of the latent factors was not valid in this larger model.

${ }^{17}$ For full list of parameter estimates and p-values, see Tables 18 and 19 in the Appendix.
} 
two different intervention measures. Comparison of the results of A2 and B2, or of A3 and B3, show that the percentage contributions coming from Brazil's intervention are strikingly similar, with less than one percentage point difference in the volatility decomposition of both the Brazilian and neighbouring currency markets.

Where intervention is directly used in the modelling framework it has a substantial impact on Brazilian currency returns, accounting for between $52.76 \%$ of return volatility in Brazil for the Argentinian model (Model A1 in Table 3) and $64.31 \%$ of return volatility for Brazil in the Chilean model (Model A2 in Table 7). For Peru, the contribution is $57.82 \%$ (Model A3 in Table 9). Again, the intervention parameter $\iota_{b r}$ for all of the models is statistically significant at the $1 \%$ level in both specifications (Table 4 and 11).

Directly using the Brazilian intervention data in the model also shows that Brazilian intervention has a small impact on the neighbouring economies, ranging from $0.01 \%$ of the contribution to the return volatility for Peru (Model A3) to 5.69\% for the return volatility for Chile (Model A2), which is the highest impact of Brazilian intervention on neighbouring economies in the range of models. The intervention parameter $\iota_{c h}$ for Chile is significant, while for Peru it is not significant.

Overall, the results so far indicate that the model of central bank intervention can be estimated using either directly measured intervention, or changes in reserves. The results of the paper show that the volatility decompositions of the effects of Brazilian intervention on the Brazilian returns are remarkably consistent regardless of the measure used, as are the effects of intervention on the returns on the neighbouring economies. The results show that it is possible to uncover the contribution of intervention to currency market volatility without necessarily knowing the precise US dollar value of the intervention. The caveat to the strength of these results however is that the models are specified conditioning on knowing when intervention occurs.

\section{Cross-Region Spillovers of Reserve Accumulation}

This section extends the analysis of the previous section by investigating the regional spillover effects of reserve accumulation through deliberate central bank intervention in the foreign exchange market using a similar factor framework to Section 2. To attest the empirical evidence of regional intervention spillover effects on foreign reserves among neighbouring countries provides further evidence on the mercantilist motive for reserve 
Table 7: Volatility Decomposition for Model A2

Notes: Contribution of each factor to total volatility, in percent. The model is estimated over the period May 4, 2009-June 29, 2012 (see eq.(1) and Table 2).

\begin{tabular}{|c|c|c|c|c|c|c|c|}
\hline & \multicolumn{6}{|c|}{ Factors } & \multirow[b]{2}{*}{ Total } \\
\hline & Global & Currency & LA-currency & Brazil & Intervention & Residual & \\
\hline \multicolumn{8}{|c|}{ Non-intervention days $(j=0)$} \\
\hline$E U R_{t}^{0}$ & 5.44 & 72.40 & - & - & - & 22.16 & 100.0 \\
\hline$G B P_{t}^{0}$ & 4.21 & 59.87 & - & - & - & 35.92 & 100.0 \\
\hline$C L P_{t}^{0}$ & 2.44 & 29.10 & 68.44 & - & - & 0.02 & 100.0 \\
\hline Cresto & 3.80 & - & - & - & - & 96.20 & 100.0 \\
\hline$B R L_{t}^{0}$ & 25.16 & 69.09 & 3.77 & 0.50 & - & 1.48 & 100.0 \\
\hline $\operatorname{Bint}_{t}^{0}$ & 0.01 & - & - & 2.50 & - & 97.49 & 100.0 \\
\hline \multicolumn{8}{|c|}{ Intervention days $(j=1)$} \\
\hline$E U R_{t}^{1}$ & 78.81 & 3.45 & - & - & - & 17.74 & 100.0 \\
\hline$G B P_{t}^{1}$ & 60.11 & 7.59 & - & - & - & 32.30 & 100.0 \\
\hline$C L P_{t}^{1}$ & 19.14 & 0.01 & 38.47 & - & 5.69 & 36.69 & 100.0 \\
\hline Cress $s_{t}^{1}$ & 0.01 & - & - & - & - & 99.99 & 100.0 \\
\hline$B R L_{t}^{1}$ & 34.96 & 0.00 & 0.00 & 0.73 & 64.31 & 0.00 & 100.0 \\
\hline $\operatorname{Bint}_{t}^{1}$ & 34.95 & - & - & 0.73 & - & 64.32 & 100.0 \\
\hline
\end{tabular}

Table 8: Volatility Decomposition for Model B2

Notes: Contribution of each factor to total volatility, in percent. The model is estimated over the period May 4, 2009-June 29, 2012 (see eq.(1) and Table 2).

\begin{tabular}{|c|c|c|c|c|c|c|c|}
\hline & \multicolumn{6}{|c|}{ Factors } & \multirow[b]{2}{*}{ Total } \\
\hline & Global & Currency & LA-currency & Brazil & Intervention & Residual & \\
\hline \multicolumn{8}{|c|}{ Non-intervention days $(j=0)$} \\
\hline$E U R_{t}^{0}$ & 69.61 & 1.18 & - & - & - & 29.22 & 100.0 \\
\hline$G B P_{t}^{0}$ & 65.95 & 6.98 & - & - & - & 27.07 & 100.0 \\
\hline$C L P_{t}^{0}$ & 40.52 & 7.90 & 44.63 & - & - & 6.95 & 100.0 \\
\hline $\mathrm{Cres}_{t}^{0}$ & 0.00 & - & - & - & - & 100.00 & 100.0 \\
\hline$B R L_{t}^{0}$ & 52.42 & 2.62 & 0.13 & 0.03 & - & 44.80 & 100.0 \\
\hline $\mathrm{Bres}_{t}^{0}$ & 42.45 & - & - & 0.05 & - & 57.50 & 100.0 \\
\hline \multicolumn{8}{|c|}{ Intervention days $(j=1)$} \\
\hline$E U R_{t}^{1}$ & 78.99 & 13.06 & - & - & - & 7.95 & 100.0 \\
\hline$G B P_{t}^{1}$ & 60.28 & 2.14 & - & - & - & 37.58 & 100.0 \\
\hline$C L P_{t}^{1}$ & 18.93 & 0.01 & 28.22 & - & 5.77 & 47.07 & 100.0 \\
\hline Crest $_{t}^{1}$ & 0.01 & - & - & - & - & 99.99 & 100.0 \\
\hline$B R L_{t}^{1}$ & 35.00 & 0.00 & 0.00 & 0.04 & 64.96 & 0.00 & 100.0 \\
\hline Brest $_{t}^{1}$ & 35.03 & - & - & 0.04 & - & 64.93 & 100.0 \\
\hline
\end{tabular}


Table 9: Volatility Decomposition for Model A3

Notes: Contribution of each factor to total volatility, in percent. The model is estimated over the period May 4, 2009-June 29, 2012 (see eq.(1) and Table 2).

\begin{tabular}{|c|c|c|c|c|c|c|c|}
\hline & \multicolumn{6}{|c|}{ Factors } & \multirow[b]{2}{*}{ Total } \\
\hline & Global & Currency & LA-currency & Brazil & Intervention & Residual & \\
\hline \multicolumn{8}{|c|}{ Non-intervention days $(j=0)$} \\
\hline$E U R_{t}^{0}$ & 99.33 & 0.67 & - & - & - & 0.00 & 100.0 \\
\hline$G B P_{t}^{0}$ & 52.54 & 3.89 & - & - & - & 43.57 & 100.0 \\
\hline$P E N_{t}^{0}$ & 18.93 & 4.94 & 44.55 & - & - & 31.58 & 100.0 \\
\hline $\operatorname{Pres}_{t}^{0}$ & 7.29 & - & - & — & - & 92.71 & 100.0 \\
\hline$B R L_{t}^{0}$ & 39.43 & 21.15 & 0.81 & 0.15 & - & 38.47 & 100.0 \\
\hline $\operatorname{Bint}_{t}^{0}$ & 0.14 & - & - & 0.71 & - & 99.15 & 100.0 \\
\hline \multicolumn{8}{|c|}{ Intervention days $(j=1)$} \\
\hline$E U R_{t}^{1}$ & 65.27 & 11.72 & - & - & - & 23.01 & 100.0 \\
\hline$G B P_{t}^{1}$ & 49.04 & 5.10 & - & - & - & 45.87 & 100.0 \\
\hline$P E N_{t}^{1}$ & 37.10 & 62.89 & 0.00 & - & 0.01 & 0.00 & 100.0 \\
\hline $\operatorname{Pres}_{t}^{1}$ & 1.51 & - & - & - & - & 98.49 & 100.0 \\
\hline$B R L_{t}^{1}$ & 41.96 & 0.00 & 0.00 & 0.21 & 57.82 & 0.00 & 100.0 \\
\hline $\operatorname{Bint}_{t}^{1}$ & 41.93 & - & - & 0.21 & - & 57.86 & 100.0 \\
\hline
\end{tabular}

Table 10: Volatility Decomposition for Model B3

Notes: Contribution of each factor to total volatility, in percent. The model is estimated over the period May 4, 2009-June 29, 2012 (see eq.(1) and Table 2).

\begin{tabular}{|c|c|c|c|c|c|c|c|}
\hline & \multicolumn{6}{|c|}{ Factors } & \multirow[b]{2}{*}{ Total } \\
\hline & Global & Currency & LA-currency & Brazil & Intervention & Residual & \\
\hline \multicolumn{8}{|c|}{ Non-intervention days $(j=0)$} \\
\hline$E U R_{t}^{0}$ & 77.82 & 0.90 & - & - & - & 21.28 & 100.0 \\
\hline$G B P_{t}^{0}$ & 63.37 & 0.24 & - & - & - & 36.39 & 100.0 \\
\hline$P E N_{t}^{0}$ & 19.19 & 11.89 & 54.30 & - & - & 14.62 & 100.0 \\
\hline $\operatorname{Pres}_{t}^{0}$ & 6.98 & - & - & - & - & 93.02 & 100.0 \\
\hline$B R L_{t}^{0}$ & 51.47 & 24.49 & 5.44 & 0.24 & - & 18.36 & 100.0 \\
\hline $\mathrm{Bres}_{t}^{0}$ & 41.37 & - & - & 0.42 & - & 58.21 & 100.0 \\
\hline \multicolumn{8}{|c|}{ Intervention days $(j=1)$} \\
\hline$E U R_{t}^{1}$ & 65.26 & 11.72 & - & - & - & 23.02 & 100.0 \\
\hline$G B P_{t}^{1}$ & 49.03 & 5.10 & - & - & - & 45.87 & 100.0 \\
\hline$P E N_{t}^{1}$ & 37.10 & 62.88 & 0.00 & - & 0.01 & 0.00 & 100.0 \\
\hline $\operatorname{Pres}_{t}^{1}$ & 1.51 & - & - & - & - & 98.49 & 100.0 \\
\hline$B R L_{t}^{1}$ & 41.93 & 0.00 & 0.00 & 0.35 & 57.72 & 0.00 & 100.0 \\
\hline Bres $_{t}^{1}$ & 41.90 & - & - & 0.34 & - & 57.76 & 100.0 \\
\hline
\end{tabular}


Table 11: Wald Tests on Intervention and Structural Breaks in Factor Models A2, B2, A3 \& B3

Notes: A bootstrap procedure (resampling 1000 times) is used to calculate the variancecovariance matrix of the parameters. The model is estimated over the period May 4, 2009June 29, 2012 (see eq.(1), Table 2 and Section 4.3). For Argentina (models A1 and B1), see Tables 4 and 6 .

\begin{tabular}{|c|c|c|c|c|}
\hline Case 2: Chile & \multicolumn{2}{|c|}{ Model A2 } & \multicolumn{2}{|l|}{ Model B2 } \\
\hline Intervention Parameter & Estimate & p-value & Estimate & p-value \\
\hline$\iota_{b r}$ & -0.754 & 0.00 & 0.756 & 0.00 \\
\hline$\iota_{c h}$ & -0.216 & 0.00 & 0.217 & 0.00 \\
\hline Wald Test Hypothesis & Test Statistics & p-value & Test Statistics & p-value \\
\hline \multicolumn{5}{|l|}{ Joint intervention parameters } \\
\hline$H_{0}: \iota_{b r}=\iota_{c h}=0$ & 198.31 & 0.00 & 145.14 & 0.00 \\
\hline$H_{0}: \iota_{b r}=\iota_{c h}=\lambda_{6, u}^{1}=0$ & 207.12 & 0.00 & 386.16 & 0.00 \\
\hline $\begin{array}{l}\text { Joint structural break parame } \\
\qquad H_{0}: \iota_{b r}=\iota_{c h}=\lambda_{i, f}^{1}=0\end{array}$ & 782.78 & 0.00 & 1329.82 & 0.00 \\
\hline Case 3: Peru & \multicolumn{2}{|c|}{ Model A3 } & \multicolumn{2}{|l|}{ Model B3 } \\
\hline Intervention Parameter & Estimate & p-value & Estimate & $\mathrm{p}$-value \\
\hline$\iota_{b r}$ & -0.714 & 0.00 & -0.713 & 0.00 \\
\hline$\iota_{p e}$ & 0.012 & 0.28 & 0.012 & 0.41 \\
\hline Wald Test Hypothesis & Test Statistics & $\mathrm{p}$-value & Test Statistics & p-value \\
\hline \multicolumn{5}{|l|}{ Joint intervention parameters } \\
\hline$H_{0}: \iota_{b r}=\iota_{c h}=0$ & 380.32 & 0.00 & 21.86 & 0.00 \\
\hline$H_{0}: \iota_{b r}=\iota_{c h}=\lambda_{6, u}^{1}=0$ & 393.63 & 0.00 & 21.91 & 0.00 \\
\hline $\begin{array}{l}\text { Joint structural break parame } \\
\qquad H_{0}: \iota_{b r}=\iota_{c h}=\lambda_{i, f}^{1}=0\end{array}$ & 976.22 & 0.00 & 254.93 & 0.00 \\
\hline
\end{tabular}


accumulation though the lens of cross-country links of reserve stocks, when the major country in the region adjusts its reserve stock through intervention.

\subsection{Model Specification}

The model for the spillover effects of intervention to neighbouring country reserves follows a similar structure to the models in Section 2. Here, $Y_{t}$ comprises the reserve changes of the neighbouring countries Argentina, Chile, and Peru, as well as Brazil's own reserves and intervention where

$$
Y_{t}^{j}=\left[\text { Ares }_{t}^{j}, \text { Cres }_{t}^{j}, \text { Pres }_{t}^{j}, \text { Bres }_{t}^{j}, \text { Bint }_{t}^{j}\right]^{\prime} \quad j=0,1,
$$

and where the reserves and intervention data are the same as that used in Sections 4.2 and 4.3.

A distinction in the sample is again imposed to differentiate non-intervention days $(j=0)$ from intervention days $(j=1)$ to isolate the contribution of Brazil's central bank currency intervention factor into the reserve changes of the neighbouring countries. On the non-intervention days $(j=0)$ the model is

$$
\left[\begin{array}{c}
\text { Ares }_{t}^{0} \\
\operatorname{Cres}_{t}^{0} \\
\operatorname{Pres}_{t}^{0} \\
\operatorname{Bres}_{t}^{0} \\
\operatorname{Bint}_{t}^{0}
\end{array}\right]=\left[\begin{array}{c}
\lambda_{1, \omega}^{0} \\
\lambda_{2, \omega}^{0} \\
\lambda_{3, \omega}^{0} \\
\lambda_{4, \omega}^{0} \\
\lambda_{5, \omega}^{0}
\end{array}\right] \omega_{t}+\left[\begin{array}{c}
0 \\
0 \\
0 \\
\lambda_{4, b r}^{0} \\
\lambda_{5, b r}^{0}
\end{array}\right] b r_{t}+\left[\begin{array}{ccccc}
\lambda_{1, u}^{0} & 0 & 0 & 0 & 0 \\
0 & \lambda_{2, u}^{0} & 0 & 0 & 0 \\
0 & 0 & \lambda_{3, u}^{0} & 0 & 0 \\
0 & 0 & 0 & \lambda_{4, u}^{0} & 0 \\
0 & 0 & 0 & 0 & \lambda_{5, u}^{0}
\end{array}\right]\left[\begin{array}{l}
u_{1, t} \\
u_{2, t} \\
u_{3, t} \\
u_{4, t} \\
u_{5, t}
\end{array}\right],
$$

and, on the intervention days $(j=1)$ is

$$
\begin{aligned}
& {\left[\begin{array}{c}
\text { Ares }_{t}^{1} \\
\text { Cres }_{t}^{1} \\
\text { Pres }_{t}^{1} \\
\text { Bres }_{t}^{1} \\
\text { Bint }_{t}^{1}
\end{array}\right]=\left[\begin{array}{c}
\left(\lambda_{1, \omega}^{0}+\lambda_{1, \omega}^{1}\right) \\
\left(\lambda_{2, \omega}^{0}+\lambda_{2, \omega}^{1}\right) \\
\left(\lambda_{3, \omega}^{0}+\lambda_{3, \omega}^{1}\right) \\
\left(\lambda_{4, \omega}^{0}+\lambda_{4, \omega}^{1}\right) \\
\left(\lambda_{5, \omega}^{0}+\lambda_{5, \omega}^{1}\right)
\end{array}\right] \omega_{t}+\left[\begin{array}{c}
0 \\
0 \\
0 \\
\lambda_{4, b r}^{0} \\
\lambda_{5, b r}^{0}
\end{array}\right] b r_{t}} \\
& +\left[\begin{array}{ccccc}
\left(\lambda_{1, u}^{0}+\lambda_{1, u}^{1}\right) & 0 & 0 & 0 & \iota_{a r} \\
0 & \left(\lambda_{2, u}^{0}+\lambda_{2, u}^{1}\right) & 0 & 0 & \iota_{c h} \\
0 & 0 & \left(\lambda_{3, u}^{0}+\lambda_{3, u}^{1}\right) & 0 & \iota_{p e} \\
0 & 0 & 0 & \left(\lambda_{4, u}^{0}+\lambda_{4, u}^{1}\right) & \iota_{b r} \\
0 & 0 & 0 & 0 & \left(\lambda_{5, u}^{0}+\lambda_{5, u}^{1}\right)
\end{array}\right]\left[\begin{array}{c}
u_{1, t} \\
u_{2, t} \\
u_{3, t} \\
u_{4, t} \\
u_{5, t}
\end{array}\right] .
\end{aligned}
$$

Similar to the previous section, the dynamics of each variable is a function of a set of orthogonal latent factors $f=\{\omega, b r, u\}$ which comprises: the global factor $\left(\omega_{t}\right)$ common 
to all variables; a Brazilian factor $\left(b r_{t}\right)$ common to Brazilian reserves and intervention; and lastly, a residual factor $\left(u_{t}\right)$, capturing the idiosyncracies of each separate market. Again, the model assumes the dynamics on intervention days differ from the nonintervention days through structural breaks on the intervention days, so that nonintervention day model is nested in the intervention day model. Furthermore, there are four extra loading parameters, $\iota_{a r}, \iota_{c h}, \iota_{p e}$ and $\iota_{b r}$ only present on the intervention days $(j=1)$, which are designed to test the impact of Brazil's central bank currency intervention in the reserve changes of the neighbouring economies of Argentina, Chile and Peru, and Brazilian reserves respectively.

\subsection{Results}

The volatility decompositions are calculated and displayed in Table 12. The top panel provides the percentage contribution of the orthogonal latent factors for the days with no central bank currency intervention in Brazil. It is clear that the residual factor dominates the reserve volatility decomposition for all of Brazil's neighbouring countries reserve changes explaining between $76.70 \%$ and $99.67 \%$ on non-intervention days, and even more of the volatility on the intervention days with all neighbouring countries above $97 \%$.

Brazil's reserve changes are dominated by the residual factor as well on nonintervention days with $57.18 \%$, while the remainder is determined by the global factor and the Brazilian factor. On the intervention days, intervention is responsible for explaining $50.77 \%$ of the volatility of Brazilian reserves. Indeed, on the intervention days, the global factor also works as a 'Brazil' country factor, since in addition to explaining $14.77 \%$ of Brazil's reserve changes, it accounts for $5.29 \%$ of Brazil's central bank intervention volatility, while barely impacting other markets. The regional spillover effects of Brazil's central bank intervention on neighbouring countries reserves are not present for any of the countries, explaining less than $1 \%$ of the volatility in these markets.

These results indicate that neighbouring countries in this sample do not respond in the short term to the mercantilism displayed in Brazil in terms of reserve accumulation or deccumulation. In fact, reserve accumulation is entirely determined by domestic concerns. Table 13 reports on the statistical significance of intervention parameters and joint structural breaks. Wald tests on the joint parameters confirm the validity of the model, including the structural break imposed on intervention days. Moreover, the intervention parameters are only statistically significant at the $10 \%$ level for Brazil 
Table 12: Cross-Region Spillovers of Reserve Accumulation Factor Model Volatility Decomposition

Notes: Contribution of each factor to total volatility, in percent. The model is estimated over the period May 4, 2009-June 29, 2012 (see Section 5).

\begin{tabular}{crrrrr}
\hline \hline & \multicolumn{5}{c}{ Factors } \\
\cline { 2 - 5 } & Global & Brazil & Intervention & Residual & Total \\
\hline Non-intervention days $(j=0)$ & 23.30 & - & - & 76.70 & 100.0 \\
Ares $_{t}^{0}$ & 0.33 & - & - & 99.67 & 100.0 \\
Cres $_{t}^{0}$ & 12.53 & - & - & 87.47 & 100.0 \\
Pres $_{t}^{0}$ & 23.67 & 19.15 & - & 57.18 & 100.0 \\
Bres $_{t}^{0}$ & 0.83 & 98.67 & - & 0.50 & 100.0 \\
Bint $_{t}^{0}$ & & & & & \\
\hline Intervention days $(j=1)$ & 2.07 & - & 0.30 & 97.63 & 100.0 \\
Ares $_{t}^{1}$ & 0.21 & - & 0.42 & 99.37 & 100.0 \\
Cres $_{t}^{1}$ & 2.01 & - & 0.60 & 97.39 & 100.0 \\
Pres $_{t}^{1}$ & 14.77 & 12.22 & 50.77 & 22.25 & 100.0 \\
Bres $_{t}^{1}$ & 5.29 & 19.52 & - & 75.19 & 100.0 \\
Bint $_{t}^{1}$ & & & & &
\end{tabular}

Table 13: Cross-Region Spillovers of Reserve Accumulation Factor Model Wald Tests of Intervention and Structural Breaks

Notes: A bootstrap procedure (resampling 1000 times) was used to calculate the variancecovariance matrix of the parameters. The model is estimated over the period May 4, 2009June 29, 2012 (see Section 5). DOF denotes degrees of freedom.

\begin{tabular}{cccc}
\hline \hline Intervention Parameter & Estimate & Standard Deviation & p-value \\
\hline$\iota_{b r}$ & 0.813 & 0.174 & 0.00 \\
$\iota_{a r}$ & 0.053 & 0.108 & 0.31 \\
$\iota_{c h}$ & 0.059 & 0.048 & 0.11 \\
$\iota_{p e}$ & 0.077 & 0.055 & 0.08 \\
\hline Wald Test Hypothesis & DOF & Test Statistic & p-value \\
\hline Joint intervention parameters & & & \\
$H_{0}: \iota_{b r}=\iota_{a r}=\iota_{c h}=\iota_{p e}=0$ & 4 & 29.57 & 0.00 \\
$H_{0}: \iota_{b r}=\iota_{a r}=\iota_{c h}=\iota_{p e}=\lambda_{5, u}^{1}=0$ & 5 & 31.53 & 0.00 \\
Joint structural break parameters & & & \\
$H_{0}: \iota_{b r}=\iota_{a r}=\iota_{c h}=\iota_{p e}=\lambda_{i, f}^{1}=0$ & 14 & 280.01 & 0.00 \\
\hline
\end{tabular}


$\left(\iota_{b r}\right)$ and Peru $\left(\iota_{p e}\right) \cdot{ }^{18}$

\subsection{Longer Horizon Strategic Reserve Accumulation}

In this Section, the reserve accumulation spillover effects stemming from Brazil's central bank intervention is analysed using data at a monthly frequency. The spillover effects to neighbouring reserve stocks of Brazilian intervention may occur at a different frequency to that considered in the model of Section 5.2 as regional central banks react in a considered fashion to changes in Brazilian reserves as they evolve over time rather than to daily movements. In the medium and long run, countries under a fairly free international capital movement environment may benefit from signalling economic prowess in comparison to its regional neighbours through foreign reserve acquisitions. Holding (relatively) strong reserves, goes the argument, helps to avoid potential currency speculative attacks (Eichengreen, 2001) and provides indirect collateral assets for foreign direct investments (Dooley et al., 2005), representing a new form of Bullionism.

The results using monthly data are in sharp contrast to the weak results of Section 5.2. The results confirm the impact of Brazil's central bank currency intervention on the neighbouring country reserve stocks, reinforcing the mercantilist motive hypothesis and motives described above. Using a monthly dataset from February 2003 until May 2012 (112 observations), the reserve accumulation factor model in equation 2 is re-estimated, with the volatility decompositions of cross-region spillovers presented in Table 14. The occurrence of intervention days are now substituted for intervention months. Accordingly, Brazil's central bank currency intervention considerably contributes to 61.4 percent of Brazil's reserve changes, 73.7 percent of Peru's reserve changes, 53.1 percent of Chile's reserve changes and 57.8 percent of Argentina's reserve changes. Tables 15 and 16 containing the Wald tests of the intervention and structural breaks and the parameter estimates confirm the statistical significance of the results at the 1 percent level.

\footnotetext{
${ }^{18}$ For full list of parameter estimates and p-values, see Table 20 in the Appendix.
} 
Table 14: Cross-Region Spillovers of Reserve Accumulation Factor Model Volatility Decomposition - Monthly Data

Notes: Contribution of each factor to total volatility, in percent. The model is estimated over the period Feb 2003-May 2012.

\begin{tabular}{crrrrr}
\hline \hline & \multicolumn{5}{c}{ Factors } \\
\cline { 2 - 5 } & Global & Brazil & Intervention & Residual & Total \\
\hline Non-intervention months $(j=0)$ & & & & & \\
Ares $_{t}^{0}$ & 83.71 & - & - & 16.29 & 100.0 \\
Cres $_{t}^{0}$ & 76.96 & - & - & 23.04 & 100.0 \\
Pres $_{t}^{0}$ & 100.00 & - & - & 0.00 & 100.0 \\
Bres $_{t}^{0}$ & 99.78 & 0.22 & - & 0.00 & 100.0 \\
Bint $_{t}^{0}$ & 29.32 & 70.68 & - & 0.00 & 100.0 \\
\hline Intervention months $(j=1)_{\text {Ares }}^{1}$ & 12.58 & - & 57.84 & 29.57 & 100.0 \\
Cres $_{t}^{1}$ & 22.44 & - & 53.14 & 24.43 & 100.0 \\
Pres $_{t}^{1}$ & 26.30 & - & 73.70 & 0.00 & 100.0 \\
Bres $_{t}^{1}$ & 21.40 & 0.33 & 61.44 & 16.83 & 100.0 \\
Bint $_{t}^{1}$ & 41.85 & 31.24 & - & 26.91 & 100.0 \\
\hline
\end{tabular}

Table 15: Cross-Region Spillovers of Reserve Accumulation Factor Model Wald Tests of Intervention and Structural Breaks - Monthly Data

Notes: A bootstrap procedure (resampling 1000 times) was used to calculate the variancecovariance matrix of the parameters. The model is estimated over the period Feb 2003 - May 2012. DOF denotes degrees of freedom.

\begin{tabular}{cccc}
\hline \hline Intervention Parameter & Estimate & Standard Deviation & p-value \\
\hline$\iota_{b r}$ & -0.841 & 0.066 & 0.00 \\
$\iota_{a r}$ & -0.702 & 0.062 & 0.00 \\
$\iota_{c h}$ & -0.671 & 0.094 & 0.00 \\
$\iota_{p e}$ & -0.817 & 0.072 & 0.00 \\
\hline Wald Test Hypothesis & DOF & Test Statistic & p-value \\
\hline Joint intervention parameters & & & \\
$H_{0}: \iota_{b r}=\iota_{a r}=\iota_{c h}=\iota_{p e}=0$ & 4 & 258.89 & 0.00 \\
$H_{0}: \iota_{b r}=\iota_{a r}=\iota_{c h}=\iota_{p e}=\lambda_{5, u}^{1}=0$ & 5 & 361.13 & 0.00 \\
Joint structural break parameters & & & \\
$H_{0}: \iota_{b r}=\iota_{a r}=\iota_{c h}=\iota_{p e}=\lambda_{i, f}^{1}=0$ & 14 & 1195.00 & 0.00 \\
\hline
\end{tabular}


Table 16: Cross-Region Spillovers of Reserve Accumulation Factor Model Parameter Estimates - Monthly Data

Notes: A bootstrap procedure (resampling 1000 times) is used to calculate the variancecovariance matrix of the parameters. The model is estimated over the period Feb 2003-May 2012.

\begin{tabular}{cccccc}
\hline \hline Parameters & Estimates & p-values & Parameters & Estimates & p-values \\
\hline$\lambda_{1, w}^{0}$ & -1.086 & 0.00 & $\lambda_{1, w}^{1}$ & 0.758 & 0.00 \\
$\lambda_{2, w}^{0}$ & -1.047 & 0.00 & $\lambda_{2, w}^{1}$ & 0.612 & 0.00 \\
$\lambda_{3, w}^{0}$ & -1.142 & 0.00 & $\lambda_{3, w}^{1}$ & 0.654 & 0.00 \\
$\lambda_{4, w}^{0}$ & -1.146 & 0.00 & $\lambda_{4, w}^{1}$ & 0.706 & 0.00 \\
$\lambda_{5, w}^{0}$ & -0.386 & 0.00 & $\lambda_{5, w}^{1}$ & 1.087 & 0.00 \\
$\lambda_{1, u}^{0}$ & -0.479 & 0.00 & $\lambda_{1, u}^{1}$ & 0.981 & 0.00 \\
$\lambda_{2, u}^{0}$ & 0.573 & 0.00 & $\lambda_{2, u}^{1}$ & -1.028 & 0.00 \\
$\lambda_{3, u}^{0}$ & 0.000 & 0.01 & $\lambda_{3, u}^{1}$ & 0.000 & 0.01 \\
$\lambda_{4, u}^{0}$ & -0.001 & 0.01 & $\lambda_{4, u}^{1}$ & 0.001 & 0.01 \\
$\lambda_{5, u}^{0}$ & 0.000 & 0.01 & $\lambda_{5, u}^{1}$ & -0.557 & 0.00 \\
$\lambda_{4, b r}^{0}$ & -0.054 & 0.01 & $\lambda_{5, b r}^{0}$ & 0.600 & 0.00 \\
$\iota_{b r}$ & -0.841 & 0.00 & $\iota_{c h}$ & -0.671 & 0.00 \\
$\iota_{p e}$ & -0.817 & 0.00 & $\iota_{a r}$ & -0.702 & 0.00 \\
\hline
\end{tabular}

\section{Conclusion}

The recent rise in central bank foreign reserve stocks around the globe has sparked lively debate on the motivation for reserve accumulation. A part of the suggested rationale lies with the mercantilist motive hypothesis. That is, countries accumulate foreign reserves in order to support export promotion by influencing exchange rates or to signal relative economic strength as a modern version of bullionism. This paper investigates the impact of the mercantilist motive hypothesis using a unique data set on daily currency intervention and reserves in Brazil and their spillover effects to regional currency and reserves markets. Overall, the results support the mercantilist approach towards influencing the exchange rate and the relative economic strength signalling argument for Brazil.

The paper investigates four main themes: First is the effect of Brazilian intervention on Brazilian currency volatility; second is the spillover effect of Brazilian intervention to regional currency markets, namely Argentina, Chile and Peru; third we investigate the usefulness of Brazilian reserve changes as a proxy for Brazilian intervention in being able to uncover the regional currency markets response to intervention; and finally, a model of cross-regional reserve relationships is investigated. 
The results support the effectiveness of Brazil's intervention in substantially explaining the volatility of its exchange rate, and to a lesser degree, some spillover effects to other Latin American currency markets. Moreover, the use of Brazil's reserve changes as a proxy for currency intervention closely mimics the results using intervention. This is an important finding as currency intervention data are usually not readily available. The caveat to the strength of these results, however, is that the models are specified conditioning on knowing when intervention occurs. The results indicate strong effects of Brazil's currency intervention on the volatility of its own reserve changes, but fail to detect short-run co-movements on neighbour's foreign reserve markets on a daily basis. However, using monthly frequency, Brazil's currency intervention does impact its neighbour's reserve build-ups, in accordance with the relative economic strength signalling argument. The results also indicate regional currency intervention spillovers on Brazil's neighbouring countries, including on their reserve build-ups.

Several important insights for domestic and regional policy settings in relation to reserve accumulation and intervention stem from this analysis. The results imply that future cost-benefit analysis for reserve accumulation should go beyond the mainstream self-insurance motive and take into account possible trade and financial gains from impacts on exchange rates, which are 'perhaps the most important asset price' in a global economy (Rose, 2011). In fact, the evidence of currency intervention spillover effects and reserve accumulation comovements suggests that policy coordination among the countries in the Latin American region may be beneficial. In particular, the evidence of reserve accumulation comovements supports the argument for the regional coordination of a supranational foreign reserve fund that mitigates the costs of reserve carrying and smooths regional currency risks. Further research should focus on these policy areas.

\section{References}

Aizenman, J. And LeE, J., 2008. Financial versus monetary mercantilism: Long-run view of large international reserves hoarding. The World Economy, (2008), 593-611.

Calvo, G. A.; Izquierdo, A.; And Loo-Kung, R., 2012. Optimal holdings of 
international reserves: Self-insurance against sudden stop. Working Paper 18219, National Bureau of Economic Research.

Dooley, M.; Folkerts-Landau, D.; And Garber, P., 2005. International financial stability: Asia, interest rates and the dollar. Technical report, Deustche Bank Collected Volume.

Dooley, M. P.; Folkerts-Landau, D.; And Garber, P. M., 2008. Will subprime be a twin crisis for the United States? Working Paper 13978, National Bureau of Economic Research.

Dooley, M. P.; Folkerts-Landau, D.; And Garber, P. M., 2009. Bretton woods II still defines the international monetary system. Working Paper 14731, National Bureau of Economic Research.

Dooley, M. P.; Garber, P. M.; And Folkerts-Landau, D., 2007. The two crises of international economics. Working Paper 13197, National Bureau of Economic Research.

Dungey, M.; Fry, R.; Gonzalez-Hermosillo, B.; Martin, V.; And Tang, C., 2010. Are financial crises alike? Technical Report WP/10/14, IMF Working Paper.

Durdu, C. B.; Mendoza, E. G.; And Terrones, M. E., 2007. Precautionary demand for foreign assets in sudden stop economies: An assessment of the new merchantilism. Working Paper 13123, National Bureau of Economic Research.

Efron, B. And Tibshirani, R., 1994. An Introduction to the Bootstrap. Chapman \& Hall/CRC.

Eichengreen, B., 2001. Comments and discussion. Brookings Trade Forum, (2001), pp. $48-68$.

Fry-McKibbin, R. A. And Wanaguru, S., 2013. Currency intervention: A case study of an emerging market. Journal of International Money and Finance, 37, 0 (2013), $25-47$.

HANSEN, L., 1982. Large sample properties of generalised method of moments estimators. Econometrica, 50 (1982), 1029-1054. 
JeAnne, O. And RAnCIERE, R., 2011. The optimal level of international reserves for emerging market countries: A new formula and some applications. The Economic Journal, 121 (September 2011), 905-930.

Menkhoff, L., 2012. Foreign exchange intervention in emerging markets: A survey of empirical studies. Diskussionspapiere der Wirtschaftswissenschaftlichen Fakultt der Leibniz Universitt Hannover dp-498, Leibniz Universitt Hannover, Wirtschaftswissenschaftliche Fakultt.

Obstfeld, M.; Shambaugh, J. C.; And Taylor, A. M., 2010. Financial stability, the trilemma, and international reserves. American Economic Journal: Macroeconomics, 2, 2 (2010), 57-94.

Rose, A. K., 2011. Exchange rate regimes in the modern era: Fixed, floating, and flaky. Journal of Economic Literature, 49 (2011), 652-72. 
APPENDIX 
Figure 3: Data Series on Exchange Rates, Currency Returns, Reserve Stock levels, Reserve Stock Changes and Intervention

a) Brazil
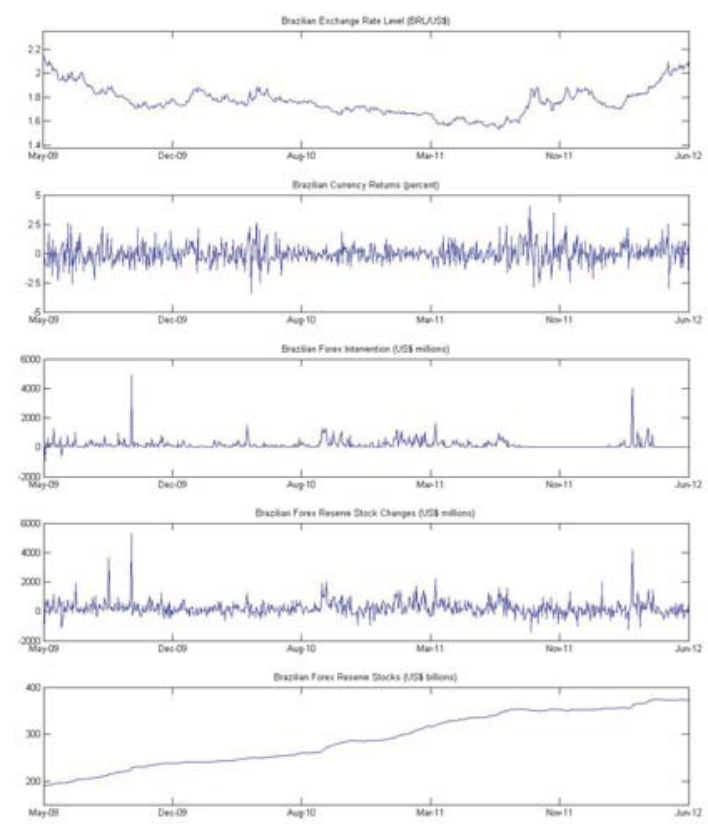

b) Argentina
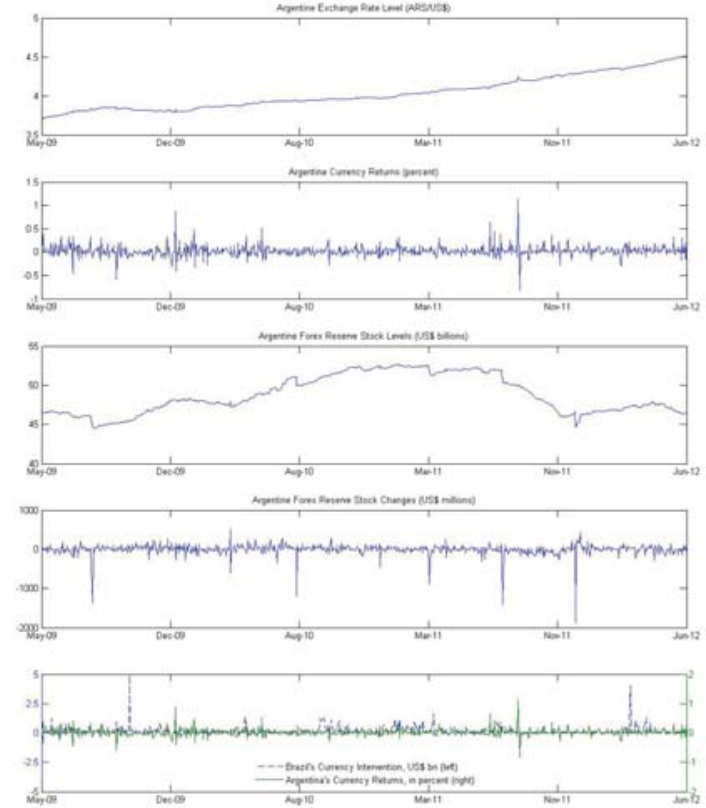

c) Chile
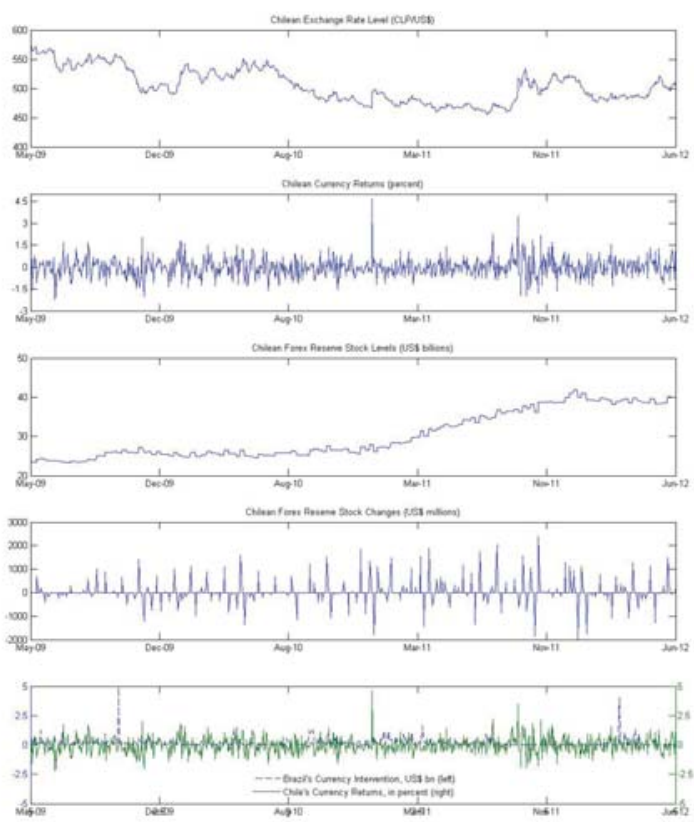

d) Peru
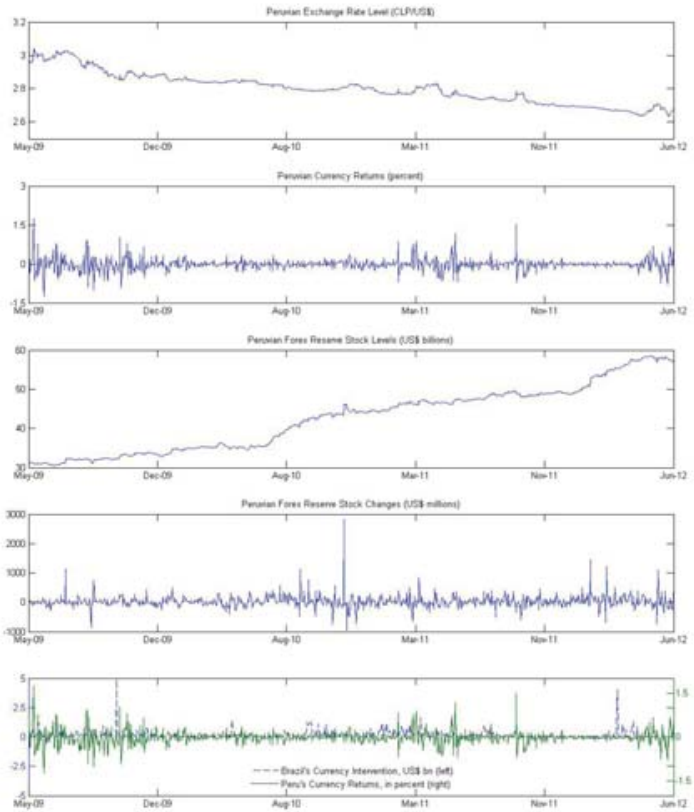
Table 17: Parameter Estimates of Factor Models A1 and B1 (see eq.(1))

\begin{tabular}{|c|c|c|c|c|}
\hline \multirow[b]{2}{*}{ Parameters } & \multicolumn{2}{|c|}{ Model A1 } & \multicolumn{2}{|c|}{ Model B1 } \\
\hline & Estimates & $\overline{\mathrm{p} \text {-values }}$ & Estimates & p-values \\
\hline$\lambda_{1, w}^{0}$ & 0.351 & 0.00 & 0.659 & 0.03 \\
\hline$\lambda_{2, w}^{0}$ & 0.310 & 0.00 & 0.583 & 0.04 \\
\hline$\lambda_{3, w}^{0}$ & 0.204 & 0.02 & 0.056 & 0.26 \\
\hline$\lambda_{4, w}^{0, w}$ & -0.580 & 0.00 & -0.317 & 0.05 \\
\hline$\lambda_{5, w}^{0}$ & 0.410 & 0.00 & 0.754 & 0.01 \\
\hline$\lambda_{6, w}^{0, \omega}$ & -0.057 & 0.10 & -0.688 & 0.03 \\
\hline$\lambda_{1, \kappa}^{0}$ & 0.797 & 0.00 & -0.596 & 0.00 \\
\hline$\lambda_{2, \kappa}^{0}$ & 0.658 & 0.00 & -0.418 & 0.02 \\
\hline$\lambda_{3, \kappa}^{0}$ & -0.151 & 0.06 & 0.151 & 0.18 \\
\hline$\lambda_{5, \kappa}^{0}$ & 0.652 & 0.00 & -0.279 & 0.12 \\
\hline$\lambda_{5, \kappa^{L A}}^{0}$ & 0.642 & 0.02 & 0.899 & 0.00 \\
\hline$\lambda_{6, \kappa^{L A}}^{0, n}$ & -0.059 & 0.20 & -0.058 & 0.30 \\
\hline$\lambda_{5, b r}^{0}$ & 0.056 & 0.25 & 0.261 & 0.22 \\
\hline$\lambda_{6, b r}^{0}$ & 0.057 & 0.25 & 0.250 & 0.24 \\
\hline$\lambda_{1, u}^{0,0 r}$ & -0.479 & 0.01 & -0.445 & 0.05 \\
\hline$\lambda_{2, u}^{0}$ & -0.534 & 0.00 & -0.547 & 0.03 \\
\hline$\lambda_{3, u}^{0}$ & -0.657 & 0.02 & -0.272 & 0.25 \\
\hline$\lambda_{4, u}^{0}$ & 0.890 & 0.02 & 1.014 & 0.00 \\
\hline$\lambda_{5, u}^{0}$ & -0.830 & 0.00 & -0.756 & 0.01 \\
\hline$\lambda_{6, u}^{0, \omega}$ & -0.501 & 0.00 & -0.421 & 0.08 \\
\hline$\lambda_{1, w}^{1}$ & -1.145 & 0.00 & -1.389 & 0.00 \\
\hline$\lambda_{2, w}^{1}$ & -1.014 & 0.00 & -1.230 & 0.00 \\
\hline$\lambda_{3, w}^{1}$ & -0.165 & 0.13 & -0.306 & 0.08 \\
\hline$\lambda_{4, w}^{1}$ & 0.668 & 0.00 & 0.406 & 0.01 \\
\hline$\lambda_{5, w}^{1, \omega}$ & -1.052 & 0.00 & -1.418 & 0.00 \\
\hline$\lambda_{6, w}^{1}$ & -0.571 & 0.04 & 0.005 & 0.37 \\
\hline$\lambda_{1, \kappa}^{1}$ & -0.187 & 0.22 & 0.236 & 0.23 \\
\hline$\lambda_{2, \kappa}^{1, \kappa}$ & -0.491 & 0.07 & -0.108 & 0.31 \\
\hline$\lambda_{3, \kappa}^{1}$ & 0.310 & 0.06 & 0.167 & 0.29 \\
\hline$\lambda_{5, \kappa}^{1, \kappa}$ & -0.678 & 0.03 & 0.249 & 0.23 \\
\hline$\lambda_{5, \kappa^{L A}}^{1}$ & -1.411 & 0.00 & -1.392 & 0.01 \\
\hline$\lambda_{6}^{1, \kappa^{L A}}$ & 0.050 & 0.25 & 0.025 & 0.35 \\
\hline$\lambda_{1, u}^{1}$ & 0.479 & 0.12 & 1.029 & 0.01 \\
\hline$\lambda_{2, u}^{1}$ & -0.209 & 0.09 & -0.069 & 0.34 \\
\hline$\lambda_{3, u}^{1}$ & 1.280 & 0.01 & -0.510 & 0.19 \\
\hline$\lambda_{4, u}^{1}$ & -1.858 & 0.00 & -1.982 & 0.00 \\
\hline$\lambda_{5, u}^{1, a}$ & 0.830 & 0.08 & 0.756 & 0.09 \\
\hline$\lambda_{6, u}^{1}$ & -0.193 & 0.14 & -0.172 & 0.27 \\
\hline$\iota_{a r}$ & -0.170 & 0.01 & 0.130 & 0.27 \\
\hline$\iota_{b r}$ & -0.681 & 0.00 & -0.608 & 0.00 \\
\hline
\end{tabular}


Table 18: Parameter Estimates of Factor Models A2 and B2 (see eq.(1))

\begin{tabular}{|c|c|c|c|c|}
\hline \multirow[b]{2}{*}{ Parameters } & \multicolumn{2}{|c|}{ Model A2 } & \multicolumn{2}{|c|}{ Model B2 } \\
\hline & Estimates & p-values & Estimates & p-values \\
\hline$\lambda_{1, w}^{0}$ & -0.232 & 0.20 & 0.829 & 0.00 \\
\hline$\lambda_{2, w}^{0}$ & -0.185 & 0.23 & 0.733 & 0.00 \\
\hline$\lambda_{3, w}^{0}$ & -0.188 & 0.22 & 0.765 & 0.00 \\
\hline$\lambda_{4, w}^{0, w}$ & -0.233 & 0.02 & 0.005 & 0.36 \\
\hline$\lambda_{5, w}^{0}$ & 0.570 & 0.03 & 0.822 & 0.00 \\
\hline$\lambda_{6, w}^{0, \omega}$ & 0.006 & 0.28 & -0.550 & 0.00 \\
\hline$\lambda_{1, \kappa}^{0, \omega}$ & 0.846 & 0.00 & -0.108 & 0.19 \\
\hline$\lambda_{2, \kappa}^{0}$ & 0.698 & 0.00 & -0.238 & 0.08 \\
\hline$\lambda_{3, \kappa}^{0}$ & 0.648 & 0.00 & 0.338 & 0.08 \\
\hline$\lambda_{5, \kappa}^{0, n}$ & 0.944 & 0.00 & 0.184 & 0.15 \\
\hline$\lambda_{5, \kappa^{L A}}^{0, n}$ & 0.994 & 0.00 & 0.803 & 0.00 \\
\hline$\lambda_{6, \kappa^{L A}}^{0, n}$ & 0.221 & 0.09 & 0.042 & 0.30 \\
\hline$\lambda_{5, b r}^{0}$ & -0.080 & 0.27 & 0.019 & 0.30 \\
\hline$\lambda_{6, b r}^{0}$ & 0.080 & 0.27 & -0.019 & 0.30 \\
\hline$\lambda_{1, u}^{0,0 r}$ & -0.468 & 0.02 & -0.537 & 0.00 \\
\hline$\lambda_{2, u}^{0}$ & -0.541 & 0.00 & 0.469 & 0.01 \\
\hline$\lambda_{3, u}^{0}$ & 0.017 & 0.31 & -0.317 & 0.18 \\
\hline$\lambda_{4, u}^{0}$ & 1.172 & 0.00 & 1.194 & 0.00 \\
\hline$\lambda_{5, u}^{0}$ & 0.138 & 0.27 & -0.760 & 0.00 \\
\hline$\lambda_{6, u}^{0, \omega}$ & -0.501 & 0.00 & -0.640 & 0.00 \\
\hline$\lambda_{1, w}^{1}$ & -0.657 & 0.01 & 0.061 & 0.21 \\
\hline$\lambda_{2, w}^{1}$ & -0.619 & 0.01 & 0.072 & 0.17 \\
\hline$\lambda_{3, w}^{1}$ & -0.208 & 0.21 & -0.371 & 0.00 \\
\hline$\lambda_{4, w}^{1}$ & 0.243 & 0.03 & -0.015 & 0.28 \\
\hline$\lambda_{5, w}^{1, \omega}$ & -1.126 & 0.00 & -0.267 & 0.03 \\
\hline$\lambda_{6, w}^{1, \omega}$ & -0.562 & 0.00 & 1.105 & 0.00 \\
\hline$\lambda_{1, \kappa}^{1}$ & -0.660 & 0.06 & -0.254 & 0.13 \\
\hline$\lambda_{2, \kappa}^{1, \kappa}$ & -0.984 & 0.01 & 0.390 & 0.08 \\
\hline$\lambda_{3, \kappa}^{1, \kappa}$ & -0.639 & 0.03 & -0.347 & 0.12 \\
\hline$\lambda_{5, \kappa}^{1, \kappa}$ & -0.942 & 0.02 & -0.186 & 0.22 \\
\hline$\lambda_{5, \kappa^{L A}}^{1}$ & -1.554 & 0.00 & -1.283 & 0.01 \\
\hline$\lambda_{6}^{1, \kappa^{L A}}$ & -0.220 & 0.24 & -0.042 & 0.30 \\
\hline$\lambda_{1, u}^{1, n}$ & 0.890 & 0.01 & 0.255 & 0.21 \\
\hline$\lambda_{2, u}^{1}$ & -0.048 & 0.28 & -1.105 & 0.00 \\
\hline$\lambda_{3, u}^{1}$ & 0.530 & 0.10 & -0.303 & 0.21 \\
\hline$\lambda_{4, u}^{1}$ & -2.079 & 0.00 & -2.102 & 0.00 \\
\hline$\lambda_{5, u}^{1}$ & -0.138 & 0.28 & 0.760 & 0.08 \\
\hline$\lambda_{6, u}^{1}$ & -0.253 & 0.08 & 1.396 & 0.00 \\
\hline$\iota_{c h}$ & -0.216 & 0.00 & 0.217 & 0.00 \\
\hline$\iota_{b r}$ & -0.7540 & 0.00 & 0.756 & 0.00 \\
\hline
\end{tabular}


Table 19: Parameter Estimates of Factor Models A3 and B3 (see eq.(1))

\begin{tabular}{|c|c|c|c|c|}
\hline \multirow[b]{2}{*}{ Parameters } & \multicolumn{2}{|c|}{ Model A2 } & \multicolumn{2}{|c|}{ Model B2 } \\
\hline & Estimates & $\mathrm{p}$-values & Estimates & p-values \\
\hline$\lambda_{1, w}^{0}$ & 0.991 & 0.00 & 0.877 & 0.00 \\
\hline$\lambda_{2, w}^{0}$ & 0.654 & 0.00 & 0.718 & 0.00 \\
\hline$\lambda_{3, w}^{0}$ & 0.392 & 0.00 & 0.395 & 0.00 \\
\hline$\lambda_{4, w}^{0}$ & -0.271 & 0.00 & -0.266 & 0.00 \\
\hline$\lambda_{5, w}^{0}$ & 0.713 & 0.00 & 0.815 & 0.00 \\
\hline$\lambda_{6, w}^{0}$ & -0.019 & 0.25 & -0.543 & 0.00 \\
\hline$\lambda_{1, \kappa}^{0}$ & -0.081 & 0.25 & 0.094 & 0.35 \\
\hline$\lambda_{2, \kappa}^{0}$ & 0.178 & 0.10 & 0.044 & 0.40 \\
\hline$\lambda_{3, \kappa}^{0}$ & 0.200 & 0.09 & 0.311 & 0.16 \\
\hline$\lambda_{5, \kappa}^{0, n}$ & 0.522 & 0.01 & -0.562 & 0.04 \\
\hline$\lambda_{5, \kappa^{L A}}^{0}$ & 0.602 & 0.02 & -0.664 & 0.03 \\
\hline$\lambda_{6, \kappa^{L A}}^{0}$ & -0.101 & 0.24 & -0.265 & 0.22 \\
\hline$\lambda_{5, b r}^{0}$ & 0.043 & 0.28 & 0.055 & 0.39 \\
\hline$\lambda_{6, b r}^{0}$ & -0.043 & 0.29 & -0.055 & 0.41 \\
\hline$\lambda_{1, u}^{0}$ & 0.001 & 0.31 & 0.459 & 0.10 \\
\hline$\lambda_{2, u}^{0, \omega}$ & -0.596 & 0.00 & 0.544 & 0.05 \\
\hline$\lambda_{3, u}^{0}$ & -0.507 & 0.05 & -0.345 & 0.21 \\
\hline$\lambda_{4, u}^{0}$ & 0.968 & 0.00 & 0.970 & 0.00 \\
\hline$\lambda_{5, u}^{0}$ & -0.704 & 0.01 & -0.487 & 0.14 \\
\hline$\lambda_{6, u}^{0}$ & -0.505 & 0.00 & -0.644 & 0.01 \\
\hline$\lambda_{1, w}^{1}$ & -1.800 & 0.00 & -1.686 & 0.01 \\
\hline$\lambda_{2, w}^{1}$ & -1.380 & 0.00 & -1.444 & 0.01 \\
\hline$\lambda_{3, w}^{1}$ & -1.024 & 0.00 & -1.027 & 0.00 \\
\hline$\lambda_{4, w}^{1}$ & 0.394 & 0.00 & 0.388 & 0.04 \\
\hline$\lambda_{5, w}^{1}$ & -1.321 & 0.00 & -1.423 & 0.00 \\
\hline$\lambda_{6, w}^{1}$ & -0.589 & 0.00 & -0.065 & 0.44 \\
\hline$\lambda_{1, \kappa}^{1}$ & -0.262 & 0.15 & 0.249 & 0.27 \\
\hline$\lambda_{2, \kappa}^{1}$ & -0.412 & 0.06 & 0.190 & 0.30 \\
\hline$\lambda_{3, \kappa}^{1}$ & 0.622 & 0.01 & -1.133 & 0.01 \\
\hline$\lambda_{5, \kappa}^{1}$ & -0.526 & 0.07 & 0.566 & 0.13 \\
\hline$\lambda_{5, \kappa^{L A}}^{1}$ & -0.602 & 0.11 & 0.664 & 0.18 \\
\hline$\lambda_{6, \kappa^{L A}}^{1}$ & 0.102 & 0.29 & 0.265 & 0.30 \\
\hline$\lambda_{1, u}^{1}$ & -0.482 & 0.03 & 0.022 & 0.42 \\
\hline$\lambda_{2, u}^{1}$ & 1.298 & 0.00 & -1.246 & 0.02 \\
\hline$\lambda_{3, u}^{1}$ & 0.507 & 0.15 & 0.345 & 0.32 \\
\hline$\lambda_{4, u}^{1}$ & -1.958 & 0.00 & -1.959 & 0.00 \\
\hline$\lambda_{5, u}^{1}$ & 0.704 & 0.15 & 0.487 & 0.23 \\
\hline$\lambda_{6, u}^{1}$ & -0.209 & 0.12 & -0.070 & 0.39 \\
\hline$\iota_{p e}$ & 0.012 & 0.28 & 0.012 & 0.41 \\
\hline$\iota_{b r}$ & -0.714 & 0.00 & -0.713 & 0.00 \\
\hline
\end{tabular}


Table 20: Cross-Region Spillovers of Reserve Accumulation Factor Model Parameter Estimates

Notes: A bootstrap procedure (resampling 1000 times) was used to calculate the variancecovariance matrix of the parameters. The model is estimated over the period May 4, 2009June 29, 2012 (see Section 5).

\begin{tabular}{cccccc}
\hline \hline Parameters & Estimates & p-values & Parameters & Estimates & p-values \\
\hline$\lambda_{1, w}^{0}$ & -0.513 & 0.09 & $\lambda_{1, w}^{1}$ & 0.373 & 0.24 \\
$\lambda_{2, w}^{0}$ & 0.067 & 0.22 & $\lambda_{2, w}^{1}$ & -0.028 & 0.33 \\
$\lambda_{3, w}^{0}$ & -0.356 & 0.05 & $\lambda_{3, w}^{1}$ & 0.215 & 0.20 \\
$\lambda_{4, w}^{0}$ & -0.411 & 0.00 & $\lambda_{4, w}^{1}$ & 0.005 & 0.35 \\
$\lambda_{5, w}^{0}$ & -0.046 & 0.22 & $\lambda_{5, w}^{1}$ & 0.309 & 0.14 \\
$\lambda_{1, u}^{0}$ & 0.931 & 0.00 & $\lambda_{1, u}^{1}$ & 0.030 & 0.38 \\
$\lambda_{2, u}^{0}$ & 1.193 & 0.00 & $\lambda_{2, u}^{1}$ & -2.097 & 0.00 \\
$\lambda_{3, u}^{0}$ & -0.940 & 0.00 & $\lambda_{3, u}^{1}$ & 1.924 & 0.00 \\
$\lambda_{4, u}^{0}$ & 0.638 & 0.00 & $\lambda_{4, u}^{1}$ & -0.246 & 0.20 \\
$\lambda_{5, u}^{0}$ & 0.036 & 0.33 & $\lambda_{5, u}^{1}$ & 0.954 & 0.00 \\
$\lambda_{4, b r}^{0}$ & 0.369 & 0.00 & $\lambda_{5, b r}^{0}$ & 0.504 & 0.00 \\
$\iota_{b r}$ & 0.813 & 0.00 & $\iota_{c h}$ & 0.059 & 0.11 \\
$\iota_{p e}$ & 0.077 & 0.08 & $\iota_{a r}$ & 0.053 & 0.31 \\
\hline
\end{tabular}

